\title{
Simulation of a Hydraulic Rod Seal with a Textured Rod and Starvation
}

\author{
Yuli Huang and Richard F. Salant* \\ George W. Woodruff School of Mechanical Engineering \\ Georgia Institute of Technology \\ Atlanta, GA 30332-0405 USA
}

\begin{abstract}
A numerical analysis of a reciprocating hydraulic rod seal with a textured rod has been performed. The sealed pressure during the instroke is elevated, while that during the outstroke is atmospheric. The analysis consists of coupled fluid mechanics, contact mechanics and load support analyses, and takes account of starvation. The fluid transport, friction force, film thickness distribution, contact pressure distribution and fluid pressure distribution in the sealing zone have been computed for a polyurethane U-cup seal. Starvation during the instroke dominates the seal behavior at moderate to high rod speeds. The results indicate the friction force exerted on the rod by the seal cannot be significantly reduced by texturing the rod, and could even be slightly increased.
\end{abstract}

KEY WORDS: elastomeric seals, reciprocating seals, texture, starvation

*- Corresponding author, 1-404-894-3176, fax 1-404-385-8535, richard.salant@ me.gatech.edu 


\section{Introduction}

The function of a rod seal is to prevent leakage from a hydraulic cylinder from entering and contaminating the environment. It is therefore one of the most critical components of a hydraulic system. The friction force exerted on the rod by the seal can be quite significant, on the order of hundreds, or even thousands of newtons, so it would be desirable to reduce such friction. The present study examines one possible means of friction reduction.

Figure 1 contains a schematic of a typical U-cup rod seal and a close-up of the sealing zone, the interface where the important sealing processes occur and where the friction force is generated. While most theoretical models of rod seals assume full film lubrication in the sealing zone, previous experimental and theoretical research has shown that mixed lubrication generally occurs [1-3]. Therefore Fig. 1 shows asperities on the seal surface in mechanical contact with the rod surface. In addition there is a micrometer scale fluid film between the two surfaces, providing lubrication.

It has been shown that the use of textured surfaces in a variety of machine elements, such as mechanical seals [4], piston rings [5, 6], journal bearings [7], and mating rigid surfaces in general $[8,9]$, can substantially reduce friction. Thus, it is reasonable to expect that a possible means of reducing the friction in a rod seal is the use of a textured rod, the focus of the present study.

However, it is important to note that rod seals differ from the above machine elements in several significant respects. While the above machine elements generally operate with full film lubrication, the rod seal operates with mixed lubrication as pointed out earlier. The above machine elements generally operate with a flooded lubricated interface. As will be shown below, 
rod seals most frequently operate with starved conditions in the sealing zone. Finally, the mating surfaces of the above machine elements are rigid, while the seal surface is elastomeric.

Some related work involving elastomeric surfaces has been done. A study of rotary elastomeric seals [10] indicates that a textured shaft could improve the sealing capability by increasing the reverse pumping rate of the seal. Research on general textured elastomeric surfaces mated with a solid surface [11] indicates that the texturing can increase the load support. In both of these areas, only full film lubrication is considered.

\section{Rod surface pattern and conceptual model}

The rod surface pattern of the present study consists of equally spaced circular microcavities across the width of the sealing zone, as shown in Fig. 2. The pattern is repeated around the circumference of the seal. The depth of the micro-cavities is $1.50 \mu \mathrm{m}$, the radius is $20 \mu \mathrm{m}$, and the land area ratios considered are $0.651,0.804$ and 0.912 . The latter land area ratios correspond to center to center micro-cavity spacings (in both the circumferential and axial directions) of $60 \mu \mathrm{m}, 80 \mu \mathrm{m}$ and $120 \mu \mathrm{m}$, respectively. As described, the micro-cavities discussed in this paper are of circular cross section. However, micro-cavities with square and triangular cross sections have also been studied, but the results are similar to those with circular cross section [12].

Figure 3 illustrates the behavior of the seal under dynamic conditions. If the seal material is elastic, it would deform into the micro-cavities, as shown in the upper sketch. However, seal materials are generally viscoelastic. For polyurethane the relaxation time is approximately $0.3 \mathrm{~s}$, while the residence time of the material adjacent to each micro-cavity is approximately $0.01 \mathrm{~s}$ to 
$0.0001 \mathrm{~s}$ for the rod speeds of interest. Therefore there is not enough time for the surface material to deform into the micro-cavities. This situation is shown on the lower sketch.

Based on these observations, the following conceptual model is used in the present study. In regions of the sealing zone adjacent to land areas, the load per unit area exerted by the seal on the interface is supported by the contact pressure plus the fluid pressure. In regions adjacent to micro-cavities, the surface remains flat and the film thickness is set equal to the micro-cavity depth plus the average of the film thickness around the periphery of the micro-cavity (on the land).

\section{Analysis}

The computational model consists of four coupled components: a fluid mechanics analysis of the lubricant film in the sealing zone, a contact mechanics analysis of the asperities on the seal surface in mechanical contact with the rod, a static contact mechanics analysis of the seal/rod interface, and a load balance in the sealing zone. A similar model has been used by the present authors in a previous study involving an untextured rod [13].

\subsection{Fluid mechanics}

The fluid mechanics analysis consists of the solution of the Reynolds Equation, Eq. (1). It is in a form that takes account of cavitation $[14,15]$, and the effect of roughness through the use of flow factors $[16,17]$. Strictly speaking, this is a transient problem as the rod surface pattern moves relative to seal. However, preliminary calculations [12] have shown that the squeeze film term in the Reynolds Equation is negligible compared to the other terms and 
therefore transient effects can be ignored. Hence the problem is treated as steady and the squeeze film term is omitted from Eq. (1).

$\frac{\partial}{\partial \hat{x}}\left(\phi_{x x} H^{3} e^{-\widehat{\alpha} F \Phi} \frac{\partial}{\partial \hat{x}}(F \Phi)\right)+\Lambda \frac{\partial}{\partial \hat{y}}\left(\phi_{y y} H^{3} e^{-\widehat{\alpha} F \Phi} \frac{\partial}{\partial \hat{y}}(F \Phi)\right)=6 \zeta \frac{\partial}{\partial \hat{x}}\left(\{1+(1-F) \Phi\}\left\{H_{T}+\right.\right.$ $\left.\left.\phi_{\text {s.c.x }}\right\}\right)$

In the liquid region

$\Phi \geq 0, F=1$ and $P_{f}=\Phi$

and in the cavitation region

$\Phi<0, F=0$ and $P_{f}=0, \hat{\rho}=1+\Phi$

Following Patir and Cheng $(16,17)$, the local film thickness is defined as

$H_{T, \text { local }}=H+\delta$

and the average truncated film thickness is given by

$H_{T}=\int_{-H}^{\infty}(H+\delta) f_{\delta}(\delta) d \delta$

where $f_{\delta}(\delta)$ is the probability density function of $\delta$.

Assuming a Gaussian distribution of asperity heights on the seal contact surface,

$f_{\delta}(\delta)=\frac{1}{\sqrt{2 \pi}} e^{-\frac{\delta^{2}}{2}}$

Solving Eq. (5) for $\mathrm{H}_{\mathrm{T}}$,

$H_{T}=\frac{H}{2}+\frac{H}{2} \operatorname{erf}\left(\frac{H}{\sqrt{2}}\right)+\frac{1}{\sqrt{2 \pi}} e^{-H^{2} / 2}$

Once Eq. (1) is solved, the volumetric flow rate can be obtained from: 
$\widehat{q}=-\phi_{x x} H^{3} e^{-\widehat{\alpha} F \Phi} \frac{\partial(F \Phi)}{\partial \hat{x}}+6 \zeta\{1+(1-F) \Phi\}\left\{H_{T}+\phi_{\text {s.c. } x}\right\}$

The fluid transport, defined as the volume of fluid carried into or out of the hydraulic cylinder during the instroke or outstroke, can be calculated by integrating $\hat{q}$ over the /instroke/outstroke time.

The average fluid shear stress on the rod and seal surfaces is given by

$\hat{\tau}_{f}=\frac{-\widehat{\sigma}}{\xi} e^{-\widehat{\alpha} F \Phi} \frac{\zeta}{H}\left(\phi_{f}-\phi_{f S S}\right)-\phi_{f p p} \frac{\widehat{\sigma}}{\xi} \frac{H}{2} \frac{\partial(F \Phi)}{\partial \hat{x}}$

All the flow factors, $\phi_{x x}, \phi_{y y}, \phi_{s . c . x}, \phi_{f}, \phi_{f s s}$ and $\phi_{f p p}$ are obtained by the method and results presented in Patir and Cheng [16, 17].

The boundary conditions in the axial direction are as follows. On the liquid side of the sealing zone $(\hat{x}=0)$, the sealed pressure is at an elevated value during the instroke, and at atmospheric during the outstroke. This corresponds to the conditions that many seal companies use to test their seals, and is close to the conditions experienced in most hydraulic cylinder applications. On the air side of the sealing zone $(\hat{x}=1)$, the pressure is initially set at atmospheric, corresponding to flooded operation. However, if it is found that the fluid transport during the instroke exceeds that during the outstroke, then the lubrication of the sealing zone must be starved during the instroke since there is not enough lubricant retained on the rod to fill the sealing zone. In such a case, the length of the pressurized portion of the sealing zone is reduced until the two fluid transports are equal, with the atmospheric pressure boundary condition applied at the end of the pressurized portion of the sealing zone. This approach to starvation is discussed in [13]. 
The Reynolds Equation is solved over a circumferential slice of the sealing zone containing a single row of micro-cavities (as shown in Fig. 2), so periodic boundary conditions are used in the circumferential direction.

Eq. (1) is discretized using the finite volume approach [18], and the resulting equations are solved using the ADI (alternating direction, implicit) method with the TDMA (tri-diagonal matrix algorithm) and the CTDMA (cyclic TDMA) algorithms. The number of nodes in the computational spatial mesh is 32480 , selected on the basis of a mesh refinement study. Going from 32480 to 64960 results in deviations of less than $0.5 \%$ in the fluid transport and friction force.

\subsection{Contact mechanics}

The mechanical contact between asperities on the seal surface and the surface of the rod is analyzed using the Greenwood-Williamson contact mechanics model. The relation between the contact pressure and the film thickness (or gap between the seal and the rod), assuming a Gaussian distribution of asperity heights, is given by

$$
P_{c}=\frac{4}{3} \frac{1}{\left(1-v^{2}\right)} \hat{\sigma}^{3 / 2} \frac{1}{\sqrt{2 \pi}} \int_{H}^{\infty}(z-H)^{3 / 2} e^{-z^{2} / 2} d z
$$

The contact pressure, together with an empirical friction coefficient, is used to compute the asperity contact friction.

$\hat{\tau}_{c}=\frac{\tau_{c}}{E}=-f P_{c}\left(\frac{\zeta}{|\zeta|}\right)$

In order to find the film thickness from the contact pressure, Eq. (10) is inverted using the polynomial regression method with the least squares approach.

$H=a+b \cdot \ln (g)+c \cdot(\ln (g))^{2}+d \cdot(\ln (g))^{3}+e \cdot(\ln (g))^{4}+j \cdot(\ln (g))^{5}$

where 


$$
\begin{aligned}
& g=-\log _{10}|I|, \mathrm{I}=\frac{P_{c}}{(4 / 3)\left(1 /\left(1-v^{2}\right) \hat{\sigma}^{3 / 2}\right)}, \text { and } a=0.86197, b=1.16979, c=0.34673, d=3.57134 \times 10^{-2}, \\
& e=1.07985 \times 10^{-3}, j=1.68629 \times 10^{-3}
\end{aligned}
$$

To find the static film thickness distribution, $H_{d c}$, the contact pressure at the static condition $P_{d c}$, is inserted into Eq. (12) for $P_{c}$.

\subsection{Static contact mechanics}

The contact pressure of an untextured (smooth) rod under static conditions, $P_{d c, s m o o t h}$, is computed using the commercial finite element code ABAQUS. A Mooney-Rivlin hyperelastic model of the polyurethane U-cup seal is used with an initial Young's modulus of $43 \mathrm{MPa}$, a Poisson's ratio of 0.499 , and the coefficients for a two parameter Mooney-Rivlin model: $C_{10}=0.2 \mathrm{MPa}, C_{01}=6 \mathrm{MPa}$, and $D=0.000279$.

CAX8R, an 8-node biquadratic axisymmetric quadrilateral, reduced integration element is selected for the seal body, while RAX2, a 2-node linear axisymmetric rigid link element is chosen for the rod and housing parts. The interaction property for calculating the contact between the seal and rod, and the seal and housing is selected as "hard" contact for pressure-over closure option, and the default constraint enforcement method is used. Additional details can be found in [12].

The static contact pressure computation is performed with the seal pressurized and mounted, but with zero fluid pressure at the interface, to yield $P_{d c \text {, smooth }}$.

\subsection{Load balance}


The load balance in the sealing zone consists of several steps. As postulated by the conceptual model (section 2), in the land area the load per unit area exerted by the seal on the interface is balanced by the contact pressure plus the fluid pressure, while in the micro-cavity area the contact pressure is zero. The latter is a consequence of the observation that, due to the long relaxation time of the seal material relative to the residence time of the material adjacent to each micro-cavity, there is not enough time for the surface material to deform into the microcavities, as discussed in Section 2.

$L=P_{c}+P_{f}$ in land area

$P_{c}=0 \quad$ in micro-cavity area

Noting that the depths of the micro-cavities are small compared to the interference mounting of the seal, it is reasonable to equate the total load on the textured rod to the total load on an untextured (smooth) rod under static conditions.

$\int_{A} L d A=\int_{A}\left(P_{c}+P_{f}\right) d A=\int_{A} P_{d c, \text { smooth }} d A$

where

$A=A_{\text {land }}+A_{\text {cav }}$

Therefore

$\int_{A_{\text {land }}} L d A=\int_{A} P_{d c, \text { smooth }} d A-\int_{A_{\text {cav }}} P_{f} d A$

Considering an infinitesimally thin layer of elastomer adjacent to the seal surface, and noting that the net force and torque on that layer must be zero, leads to

$L / P_{d c, \text { smooth }} \approx$ constant

Combining equations (14)-(19)

$P_{c}=\left\{1+\frac{\int_{A_{c a v}\left(P_{d c, s m o o t h}-P_{f}\right) d A}}{\int_{A_{\text {land }}} P_{d c, \text { smooth }} d A}\right\} P_{d c, \text { smooth }}-P_{f}$ 
It should be noted that the use of a load balance eliminates the need for the direct computation of the seal deformation during motion of the rod.

\subsection{Computational procedure}

For each case of interest, it is initially assumed that the sealing zone is flooded. The basic computational procedure for flooded lubrication is shown in Fig. 4. First, the seal and fluid properties are input. Then the static contact mechanics analysis is performed on an untextured (smooth) rod using ABAQUS to obtain the static contact pressure distribution, $P_{d c, s m o o t h}$. Next an initial guess of the film thickness, $H=H_{d c}$, is made. Using that guess, the Reynolds Equation, Eq. (1), is solved for the fluid pressure, $P_{f}$. Next, the load balance, Eq. (20), is used to compute the contact pressure, $P_{c}$. The film thickness, $H$, is then computed from the contact mechanics analysis, Eq. (12), and is compared to the guessed film thickness (or the computed film thickness from the previous iteration). If the deviation exceeds an acceptable error value, the fluid mechanics and succeeding analyses are repeated and iteration proceeds until convergence. Once convergence is achieved, auxiliary calculations are performed to obtain the fluid transport using Eq. (8) and the friction force using Eqs. (9) and (11).

If the above computations indicate that the fluid transport during the instroke exceeds that during the outstroke, starvation occurs, as pointed out in Section 3.1. The computational procedure for starvation is shown in Fig. 5. The basic computational procedure, as described above is used, but applied to a progressively shortened pressurized portion of the sealing zone, until the fluid transports during instroke and outstroke are equal. In the starved region of the sealing zone, the film thickness is set equal to $H_{d c}$. 


\section{Results}

The values of the principal parameters used in the computations are given in Table 1. The computations have shown that for different rod (and surface pattern) locations relative to the seal, the differences in the important dependent variables (fluid transports, friction force, film thickness, contact pressure, fluid pressure) are minimal [12]. Therefore, the results presented below are those obtained for a single arbitrary rod location.

\subsection{Fluid Transport}

Figure 6 shows the fluid transport as a function of rod speed for various values of the land area ratio, assuming flooded lubrication. The depth of the micro-cavities is fixed at $1.5 \mu \mathrm{m}$.

The fluid transport during the instroke increases with rod speed, and is weakly dependent on the land area ratio. The transport during the outstroke remains almost constant as the rod speed increases (for the speed range of interest), and increases with increasing land area ratio.

For each value of land area ratio, there is a critical speed, below which the outstroke fluid transport exceeds the instroke transport and the seal leaks. Above the critical speed, the instroke transport exceeds the outstroke transport and there is no net leakage. However, as pointed out in Section 3.1, the latter condition indicates starved lubrication.

During the outstroke, the fluid required to lubricate the sealing zone is directly supplied from the cylinder and is sufficient to fill the sealing zone, which is therefore flooded. However, the fluid supplied to the sealing zone during the instroke is the fluid that has been deposited on the rod during the preceding outstroke, and therefore the fluid transport during the instroke cannot exceed that during the outstroke. Thus, when the critical speed is exceeded during the instroke, there is insufficient fluid to fill the sealing zone and the lubrication must be starved. 
The difference between the instroke fluid transport and outstroke fluid transport, under flooded conditions, is a measure of the severity of the starvation and can be defined as the “degree of starvation." When this degree of starvation is positive, starvation occurs during the instroke. The higher the degree of starvation, the more severe is the starvation, as will be seen in Sections 4.4 and 4.5. From Fig. 6 it is seen that the degree of starvation for the textured rod with a 0.651 land area ratio is significantly higher than that for the untextured rod. The other textured rods with higher land area ratios result in degrees of starvation close to that of the untextured rod; for some rod velocities and land area ratios, they are slightly higher, and for some, slightly lower. It is also seen that in general the higher the rod speed, the higher the degree of starvation. Figure 7 shows the fluid transport vs. rod speed curves, taking account of starvation. Above the critical speed the instroke and outstroke transports are equal. Below the critical speed, the curves are identical to those in Fig. 6. It is noted that the critical speed is weakly dependent on land area ratio.

\subsection{Friction force}

The friction force exerted by the seal and lubricant film on the rod is shown in Fig. 8 as a function of rod speed, for various values of the land area ratio, taking account of starvation. Details of the computations [12] indicate that the friction force is produced primarily by the contacting asperities; the viscous friction is negligible.

The outstroke friction force is relatively low and substantially independent of rod speed. This is because the sealed pressure is atmospheric and the fluid pressures in the sealing zone are very low and most of the sealing zone is cavitated, for the speed range of interest. 
For the 0.651 land area ratio, the instroke friction force is higher than that for the untextured rod. For all the other higher land area ratios, the friction force is close to that of the untextured rod, sometimes a little higher, sometimes a little lower, depending on the rod speed and land area ratio. These results are consistent with the degree of starvation, discussed in Section 4.1. The higher the degree of starvation, the higher is the friction force.

As the rod speed is increased, the instroke friction force increases. This, again, is consistent with the degree of starvation. At the highest speeds, there is virtually no difference in the friction force between the smooth and textured rods. This is because there is so much starvation at those speeds that the differences in degree of starvation make little difference in the friction force, as will be seen in the subsequent sections.

The physical reasons for the above-described behavior of the friction force can be elucidated by considering the details of the sealing zone, discussed below.

\subsection{Film thickness, fluid pressure, contact pressure, outstroke}

The film thickness, fluid pressure, and contact pressure distributions during the outstroke for the untextured and textured rods at a rod speed of $0.3 \mathrm{~m} / \mathrm{s}$ are shown in Figs. 9 and 10. The distributions at the lower speeds are virtually identical to these [12.

In Fig. 9 only the film thickness in the land areas is shown; that in the micro-cavities is omitted for clarity (the breaks in the curves correspond to the micro-cavity locations). It is seen that the values of the film thickness are significantly below $3 \sigma$, indicating that mixed lubrication occurs in the sealing zone, as expected. As can be seen from the figure, the lower the land area ratio, the thinner is the film. 
From Fig. 10 it is seen that the fluid pressure is at or below atmospheric, and zero over most of the sealing zone. Computations indicate that most of the film is cavitated.

Figure 10 also shows the contact pressure distribution during the outstroke. It is seen that the lower the land area ratio, the higher is the contact pressure. This is because with a reduced land area there is a smaller area available to support the load exerted by the seal on the interface.

\subsection{Film thickness, instroke}

The film thickness distributions during the instroke for the untextured and textured rods at rod speeds of $0.03 \mathrm{~m} / \mathrm{s}, 0.10 \mathrm{~m} / \mathrm{s}$ and $0.30 \mathrm{~m} / \mathrm{s}$ are shown in Figs. $11 \mathrm{a}-11 \mathrm{c}$.

As was the case during the outstroke, the values of the film thickness are significantly below $3 \sigma$, indicating that mixed lubrication occurs in the sealing zone. The lower the land area ratio, the thinner is the film.

The boundaries of the starved region are clearly seen in these figures. The higher the speed, the larger is the starved region and the smaller the pressurized region. At $0.03 \mathrm{~m} / \mathrm{s}$ only the 0.651 land area ratio case is starved. At $0.10 \mathrm{~m} / \mathrm{s}$ all cases are starved, with the 0.651 land area ratio case having the largest starved region (smallest pressurized region) and all the other cases, including the untextured case, having about the same size smaller starved region. These results are consistent with the values of the degree of cavitation. At $0.30 \mathrm{~m} / \mathrm{s}$ all of the cases have about the same size starved region. The starvation is so severe that the differences in the degrees of cavitation make little difference in the starved boundary. The pressurized region occupies only about ten percent of the sealing zone.

\subsection{Fluid pressure, instroke}


The fluid pressure distributions during the instroke for the untextured and textured rods at rod speeds of $0.03 \mathrm{~m} / \mathrm{s}, 0.10 \mathrm{~m} / \mathrm{s}$ and $0.30 \mathrm{~m} / \mathrm{s}$ are shown in Figs. $12 \mathrm{a}-12 \mathrm{c}$. The ripples in the curves for the textured rods are due to the hydrodynamic action of the micro-cavities. These pressure fluctuations are small compared to the magnitude of the fluid pressure.

At $0.03 \mathrm{~m} / \mathrm{s}$ all the cases except for the 0.651 land area case experience flooded lubrication and have elevated fluid pressures distributed over the entire sealing zone. For the 0.651 case, due to starvation, elevated pressures are distributed over a smaller pressurized region and atmospheric pressure exists in the starved region. At $0.1 \mathrm{~m} / \mathrm{s}$ all the cases exhibit starvation, with only the reduced pressurized region containing elevated pressures, and with atmospheric pressure in the starved region. The pressurized region is smallest for the 0.651 case and about the same size for all the other cases. These results are consistent with the values of the degree of starvation. At $0.3 \mathrm{~m} / \mathrm{s}$ the pressurized region has shrunk further, to about the same size for all the cases.

\subsection{Contact pressure, instroke}

The contact pressure distributions (on the land areas) during the instroke for the untextured and textured rods at rod speeds of $0.03 \mathrm{~m} / \mathrm{s}, 0.10 \mathrm{~m} / \mathrm{s}$ and $0.30 \mathrm{~m} / \mathrm{s}$ are shown in Figs.13a - 13c. These contact pressures are especially important because the friction force is primarily generated by contacting asperities, as stated in Section 4.2.

At $0.03 \mathrm{~m} / \mathrm{s}$ the contact pressures for the 0.912 and 0.804 land area cases exceed that of the untextured case, due to the fact that the reduced land areas must support the same load, as was mentioned in connection with the outstroke; the smaller the land area, the higher is the contact pressure. The highest contact pressures occur for the 0.651 case. Here there are two 
factors causing the increased contact pressure: the reduced land area and the occurrence of starvation. In the starved region the fluid pressure is not elevated above atmospheric so the asperities must support a higher fraction of the load as compared to the flooded cases.

At 0.10 and $0.30 \mathrm{~m} / \mathrm{s}$ all of the cases are starved and the contact pressures increase as the land areas decrease.

\subsection{Effects of micro-cavity depth}

Figure 14 shows the fluid transport vs. rod speed curves under flooded conditions, for a land area ratio of 0.651 and various micro-cavity depths. The shapes of the curves are similar to those in Fig. 6. However, while Fig. 6 shows that the land area ratio has an effect on the outstroke transport, Fig. 14 shows that the micro-cavity depth has little effect on the outstroke transport. The corresponding plots of fluid transport under starved conditions (for the instroke) are contained in Fig. 15.

The friction force vs. rod speed curves are shown in Fig. 16. It is seen that the $1.0 \mu \mathrm{m}$ and1.5 $\mu \mathrm{m}$ depths produce about the same friction force, while the $0.5 \mu \mathrm{m}$ depth produces a slightly higher force. All depths produce friction forces higher than that of the untextured rod.

\section{Discussion}

As pointed out in Section 1, the objective of the present study is the evaluation of surface texturing as a means of friction reduction in hydraulic rod seals. Such possible reduction has been suggested by the apparent success of surface texturing in other types of machine elements. However, the results of the present study show that for the conditions examined, texturing cannot 
significantly reduce friction, and can even slightly increase it. There are several reasons for this result. The principal reason is related to the effect of surface micro-cavities on starvation.

The present study considers the case of elevated sealed pressure during the instroke and atmospheric sealed pressure during the outstroke. This corresponds to the conditions that many seal companies use to test their seals, and is close to the conditions experienced in most hydraulic cylinder applications. Under such conditions, above a very low rod speed the lubrication of the rod-seal interface is starved during the instroke [13]. Not enough fluid is transported out of the hydraulic cylinder during the preceding instroke and deposited on the rod, to fully fill the rod-seal interface with pressurized fluid during the instroke. Only a portion of the sealing zone is filled with pressurized fluid, while the rest of the sealing zone, the starved region, remains at atmospheric pressure. In the starved region there is no load support provided by the fluid, so the contact pressures and friction are higher than they would be if fully flooded conditions existed throughout the sealing zone. The more severe the starvation, the higher would be the friction.

The presence of micro-cavities increases the severity of the starvation. As discussed in Section 4 and in [13], the severity of starvation can measured by the "degree of starvation," the difference between the instroke fluid transport under flooded conditions and the outstroke fluid transport. The instroke fluid transport under flooded conditions is the amount of outstroke fluid transport that would be necessary in order to actually have flooded lubrication during the instroke. The larger the degree of starvation, the more severe is the starvation, meaning the shorter the region of pressurized fluid in the sealing zone during the instroke.

From Fig. 6 it is seen that the primary effect of the presence of micro-cavities is to decrease the outstroke fluid transport, and thereby increase the degree of starvation. (The 
instroke fluid transport is also decreased, but to a much smaller extent.) The larger the surface area occupied by the micro-cavities and the lower the land area ratio Ar, the larger is the degree of starvation. By reducing the land area, the presence of micro-cavities increases the contact pressures on the lands, since a smaller area is available to support the load on the interface exerted by the seal. From Eqs. 9 and 10 it is seen that the higher contact pressures will lead to smaller film thicknesses, and in particular, to a smaller minimum film thickness and therefore a lower fluid transport. These reductions in film thickness for both the outstroke and instroke can be seen in Figs. 9 and 11. However the reductions in film thickness and fluid transport are much more significant for the outstroke than for the instroke because for the outstroke the almost sole load support is provided by the contact pressure, while for the instroke load support is also provided by the fluid pressure. Thus, the presence of the micro-asperities leads to an increase in the degree of starvation during the instroke, and consequent increase in the friction. It also reduces the size of lubricated region of the sealing zone where texturing could possibly act. It is therefore not surprising that the results of the present study differ from the studies of the machine elements cited in Section 1, mechanical seals [4], piston rings [5, 6], journal bearings [7], and mating rigid surfaces in general $[8,9]$, since those studies do not include starvation.

Another reason that texturing cannot significantly reduce friction in rod seals is related to the relatively small hydrodynamic pressure elevations due to the presence of micro-cavities when one mating surface is readily deformable. In the machine elements cited in Section 1, both mating surfaces are rigid and the texturing can hydrodynamically produce significant effects on the fluid pressure. In the rod seal, the seal material is readily deformable. Based on the pressure calculations in [11], even for the highest speed considered in the present study, the pressure elevation due to a micro-cavity would be much less than a pascal. While the hydrodynamic 
pressure elevations computed in the present study (Section 4.5) are somewhat larger, they are still quite small. So, even at the lowest speeds where starvation is not encountered, the microcavities would not produce significant effects.

\section{Conclusions}

The results of this study indicate, for the conditions considered, the friction force exerted on the rod by the rod seal cannot be significantly reduced by texturing the rod, and could even be slightly increased. The reason for this is two-fold. At low rod speeds, the hydrodynamic effects on fluid pressure in the sealing zone are small compared to the fluid pressures encountered in hydraulic cylinder applications. At moderate and high rod speeds, the seal behavior is dominated by starvation, which tends to increase the friction and reduce the size of the lubricated region of the sealing zone where texturing could possibly act.

\section{Acknowledgments}

The authors gratefully acknowledge the financial support of the National Science Foundation, Engineering Research Center for Compact and Efficient Fluid Power; and the Georgia Power Company.

\section{References}

[1] Kawahara, Y., Ohtake, Y., and Hirabayashi, H., "Oil film formation of oil seals for reciprocating motion," Proc. 9th BHRA International Conference on Fluid Sealing, Noordwijkerhout, The Netherlands, April 1-3, C2, 1981. 
[2] Kanters, A. F. C., and Visscher, M., "Lubrication of reciprocating seals: experiments on the influence of surface roughness on friction and leakage," Proc. 15th Leeds-Lyon Symposium on Tribology, Vienna, Austria, September 4-7, pp. 69-77, 1988.

[3] Salant, R. F., Maser, N. and Yang, B., "Numerical model of a reciprocating hydraulic rod seal,” Journal of Tribology, vol. 129, pp. 91-97, 2007.

[4] Etsion, I and Halperin, G, "A laser surface textured hydrostatic mechanical seal," Tribology Transactions, vol. 45 (3), pp. 430-434, 2002.

[5] Kligerman, Y, Etsion, I. and Shinkarenko, A. "Improving tribological performance of piston rings by partial surface texturing," Journal of Tribology, vol. 127, pp. 632-638, 2005.

[6] Ryk. G. and Etsion, I. "Testing piston rings with partial laser surface texturing for friction reduction," Wear, vol. 261, pp. 792-796, 2006.

[7] Kango, S, Singh, D. and Sharma, R. K., "Numerical investigation on the influence of surface texture on the performance of a hydrodynamic journal bearing," Meccanica, vol. 47, pp. 469482, 2012.

[8] Wakuda, M, Yamauchi, Y., Kanzaki, Y. and Yasuda, Y, "Effect of surface texturing on friction reduction between ceramic and steel materials under lubricated sliding contact," Wear, vol. 254, pp. 356-363, 2003.

[9] Scaraggi, M., Mezzapes, F. P., Carbone, G., Sorgente, D. and Lugara, P. M., "Minimize friction of lubricated laser-microtextured-surfaces by tuning microholes depth," Tribology International, vol. 75, pp. 123-127, 2014. 
[10] Li, W., Stephens, L. S., and Wenk, J. F., "Experimental benchmarking of the numerical model of a radial lip seal with a surface textured shaft," Tribology Transactions, vol. 56, pp. 7587, 2013.

[11] Shinkarenko, A., Kligerman, Y. and Etsion, I., "The effect of surface texturing in soft elasto-hydrodynamic lubrication," Tribology International, vol. 42, pp. 284-292, 2009.

[12] Huang, Y., "Elastohydrodynamic Model of Hydraulic Rod Seals with Various Rod Surfaces,” Ph.D. Dissertation, Georgia Institute of Technology, 2014.

[13] Huang, Y. and Salant, R. F., "Numerical analysis of a hydraulic rod seal: Flooded vs. starved conditions,” Tribology International, vol. 92, pp. 577-584, 2015.

[14] Payvar, P. and Salant, R. F., "A Computational method for cavitation in a wavy mechanical seal,” Journal of Tribology, vol. 114, pp. 199-204.

[15] Xiong, S. and Wang, Q. J., "Steady-state hydrodynamic lubrication modeled with the Payvar-Salant mass conservation model,” Journal of Tribology, vol. 134, pp. 031703-1 031703-16.

[16] Patir N., and Cheng, H. S., "Average flow model for determining effects of 3-dimensional roughness on partial hydrodynamic lubrication," Journal of Lubrication TechnologyTransactions of the ASME, vol. 100, pp. 12-17, 1978.

[17] Patir, N. and Cheng, H. S., "Application of average flow model to lubrication between rough silding surfaces," Journal of Lubrication Technology-Transactions of the ASME, vol. 101, pp. 220-230, 1979.

[18] Patankar, S. V., Numerical heat transfer and fluid flow. Washington: Hemisphere Pub. Corp., 1980. 


\section{Nomenclature}

Ar land area ratio, land area/total surface area

D micro-cavity depth

E elastic modulus

F cavitation index, 1 when $\Phi \geq 0,0$ when $\Phi<0$

$f \quad$ friction coefficient for asperity contact

$f_{\delta}(\delta) \quad$ probability density function of $\delta$

$H \quad$ dimensionless nominal film thickness, $h / \sigma$

$H_{d c} \quad$ dimensionless dry contact film thickness (when there is no fluid pressure in interface), $h_{d c} / \sigma$

$H_{T} \quad$ dimensionless average truncated film thickness, $h_{T} / \sigma$

$H_{T, \text { local }} \quad$ dimensionless local film thickness, $h_{T, \text { local }} / \sigma$

$l \quad$ load per unit area

$L \quad$ length of solution domain in x-direction

$p_{a} \quad$ ambient pressure

$P_{c} \quad$ dimensionless contact pressure, $p_{c} / E$

$P_{d c, \text { smooth }} \quad$ dimensionless dry static contact pressure (when there is no fluid pressure in interface), $p_{d c} / E$

$P_{f} \quad$ dimensionless fluid pressure, $p_{f} / p_{a}$ 
dimensionless volumetric flow rate per unit circumferential length,

$$
12 \mu_{0} q L /\left(p_{a} \sigma^{3}\right)
$$

$Q$

fluid transport

$Q_{\text {out }}$

fluid transport during outstroke

$R$

asperity radius

$U$

surface speed of rod

$\hat{x}$

dimensionless axial coordinate, $x / L$

$\hat{\alpha}$

$\alpha^{*}$

dimensionless pressure-viscosity coefficient, $\alpha p_{a}$

$\beta$

dimensionless asperity radius, $R / \sigma$

$\delta$

$\Phi$

dimensionless asperity density, $\eta R^{2}$

$\delta$

dimensionless roughness height (with respect to $\sigma$

fluid pressure/density function, $P$ when $F=1, \hat{\rho}-1$ when $F=0$

$\phi_{f}, \phi_{f s s}, \phi_{f p p} \quad$ shear stress factors

$\phi_{s . c . x} \quad$ shear flow factor

$\phi_{x x}, \varphi_{y y} \quad$ pressure flow factors

$\mu_{0} \quad$ dynamic viscosity at atmospheric pressure

$\hat{\rho} \quad$ dimensionless density, $\rho / \rho_{l}$

$\rho_{l} \quad$ liquid density

$\hat{\sigma} \quad$ dimensionless rms roughness of sealing element surface, $\sigma R^{1 / 3} \eta^{2 / 3}$

$\hat{\tau}_{f} \quad$ average dimensionless viscous shear stress in the x-direction, $\tau_{f} / E$

$\hat{\tau}_{c} \quad$ dimensionless shear stress due to contacting asperities, $\tau_{c} / E$ 


$$
\begin{array}{ll}
v & \text { Poisson's ratio } \\
\xi & R^{1 / 3} \eta^{2 / 3} E L / p_{a} \\
\zeta & \text { dimensionless rod speed, } \mu_{0} U L /\left(p_{a} \sigma^{2}\right) \\
\eta & \text { asperity density }
\end{array}
$$

\section{Table and Figure Captions}

\section{Table $1 \quad$ Base parameters}

Figure $1 \quad$ Schematic of U-cup seal and sealing zone

Figure 2 Rod surface pattern

Figure 3 Dynamic behavior of seal surface

Figure $4 \quad$ Basic computational procedure

Figure $5 \quad$ Computational procedure with starvation

Figure $6 \quad$ Fluid transport vs. rod speed, flooded, $d=1.5 \mu \mathrm{m}$

Figure $7 \quad$ Fluid transport vs. rod speed, starved, $d=1.5 \mu \mathrm{m}$

Figure $8 \quad$ Friction force vs. rod speed, $d=1.5 \mu \mathrm{m}$

Figure $9 \quad$ Film thickness distribution, outstroke, $d=1.5 \mu \mathrm{m}, \mathrm{U}=0.03 \mathrm{~m} / \mathrm{s}$

Figure $10 \quad$ Fluid pressure and contact pressure distributions, outstroke, $\mathrm{d}=1.5 \mu \mathrm{m}, \mathrm{U}=0.03 \mathrm{~m} / \mathrm{s}$

Figure 11a Film thickness distribution, instroke, $d=1.5 \mu \mathrm{m}, \mathrm{U}=0.03 \mathrm{~m} / \mathrm{s}$

Figure $11 \mathrm{~b} \quad$ Film thickness distribution, instroke, $\mathrm{d}=1.5 \mu \mathrm{m}, \mathrm{U}=0.10 \mathrm{~m} / \mathrm{s}$

Figure 11c Film thickness distribution, instroke, $d=1.5 \mu \mathrm{m}, \mathrm{U}=0.30 \mathrm{~m} / \mathrm{s}$

Figure 12a Fluid pressure distribution, instroke, $d=1.5 \mu \mathrm{m}, \mathrm{U}=0.03 \mathrm{~m} / \mathrm{s}$ 
Figure $12 \mathrm{~b} \quad$ Fluid pressure distribution, instroke, $d=1.5 \mu \mathrm{m}, \mathrm{U}=0.10 \mathrm{~m} / \mathrm{s}$

Figure 12c Fluid pressure distribution, instroke, $d=1.5 \mu \mathrm{m}, \mathrm{U}=0.30 \mathrm{~m} / \mathrm{s}$

Figure 13a Contact pressure distribution, instroke, $d=1.5 \mu \mathrm{m}, \mathrm{U}=0.03 \mathrm{~m} / \mathrm{s}$

Figure 13b Contact pressure distribution, instroke, $d=1.5 \mu \mathrm{m}, \mathrm{U}=0.10 \mathrm{~m} / \mathrm{s}$

Figure 13c Contact pressure distribution, instroke, $d=1.5 \mu \mathrm{m}, \mathrm{U}=0.30 \mathrm{~m} / \mathrm{s}$

Figure 14 Fluid transport vs. rod speed, flooded, $\mathrm{Ar}=0.651$

Figure $15 \quad$ Fluid transport vs. rod speed, starved, $\mathrm{Ar}=0.651$

Figure $16 \quad$ Friction force vs. rod speed, $\mathrm{Ar}=0.651$ 
Table I

\begin{tabular}{|c|c|}
\hline Seal type & U-cup seal \\
\hline Seal material & Polyurethane \\
\hline Elastic modulus & $43 \mathrm{MPa}$ \\
\hline Poisson's ratio & 0.499 \\
\hline Sealed pressure & $\begin{array}{c}6.89 \mathrm{MPa}(1000 \mathrm{psi}) \text { during instroke; } \\
0.10 \mathrm{MPa} \text { (atmospheric) during } \\
\text { outstroke; cavitation pressure: } 0\end{array}$ \\
\hline Rod diameter & $44.45 \mathrm{~mm}$ \\
\hline $\begin{array}{c}\text { Dry friction } \\
\text { coefficient }\end{array}$ & 0.25 \\
\hline Reference viscosity & $0.043 \mathrm{~Pa} \mathrm{~s}$ \\
\hline $\begin{array}{c}\text { Pressure-viscosity } \\
\text { coefficient }\end{array}$ & $20 \times 10^{-1} \mathrm{~Pa}$ \\
\hline Seal rms roughness & $0.8 \mu \mathrm{m}$ \\
\hline $\boldsymbol{\alpha}$ & 1.25 \\
\hline $\boldsymbol{\beta}$ & 1.0 \\
\hline Stroke length & $228.6 \mathrm{~mm}$ \\
\hline Rod speed & $0.01-0.3 \mathrm{~m} / \mathrm{s}$ \\
\hline
\end{tabular}


Fig. 1

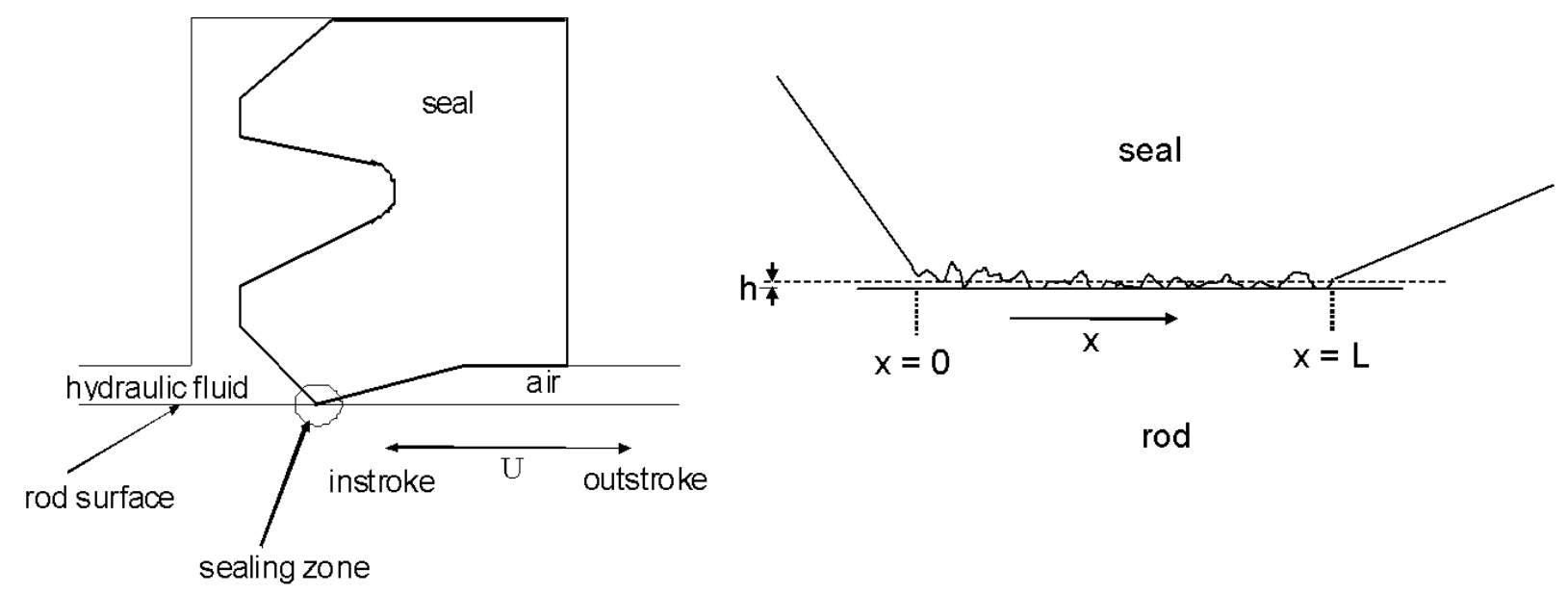


Fig. 2

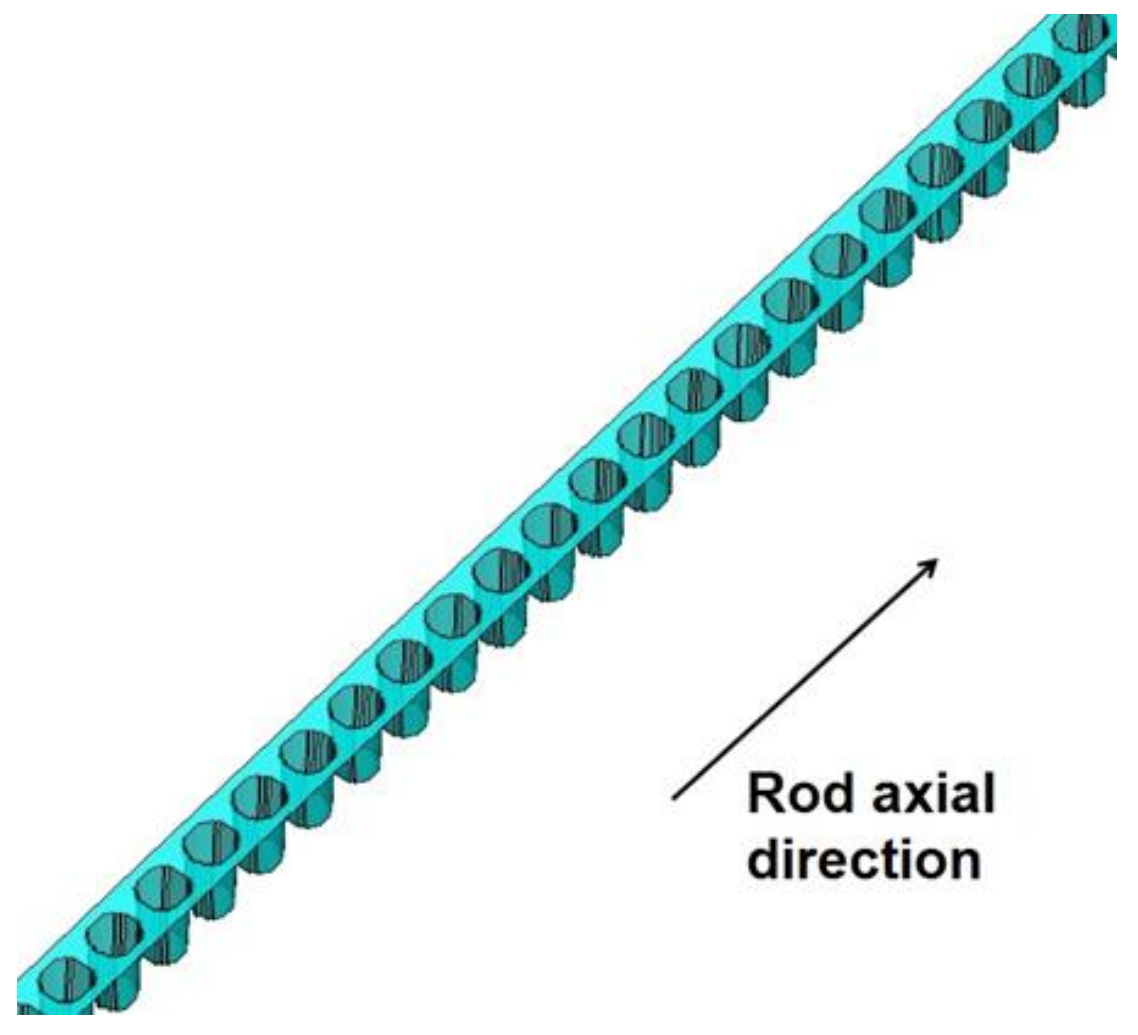


Fig. 3
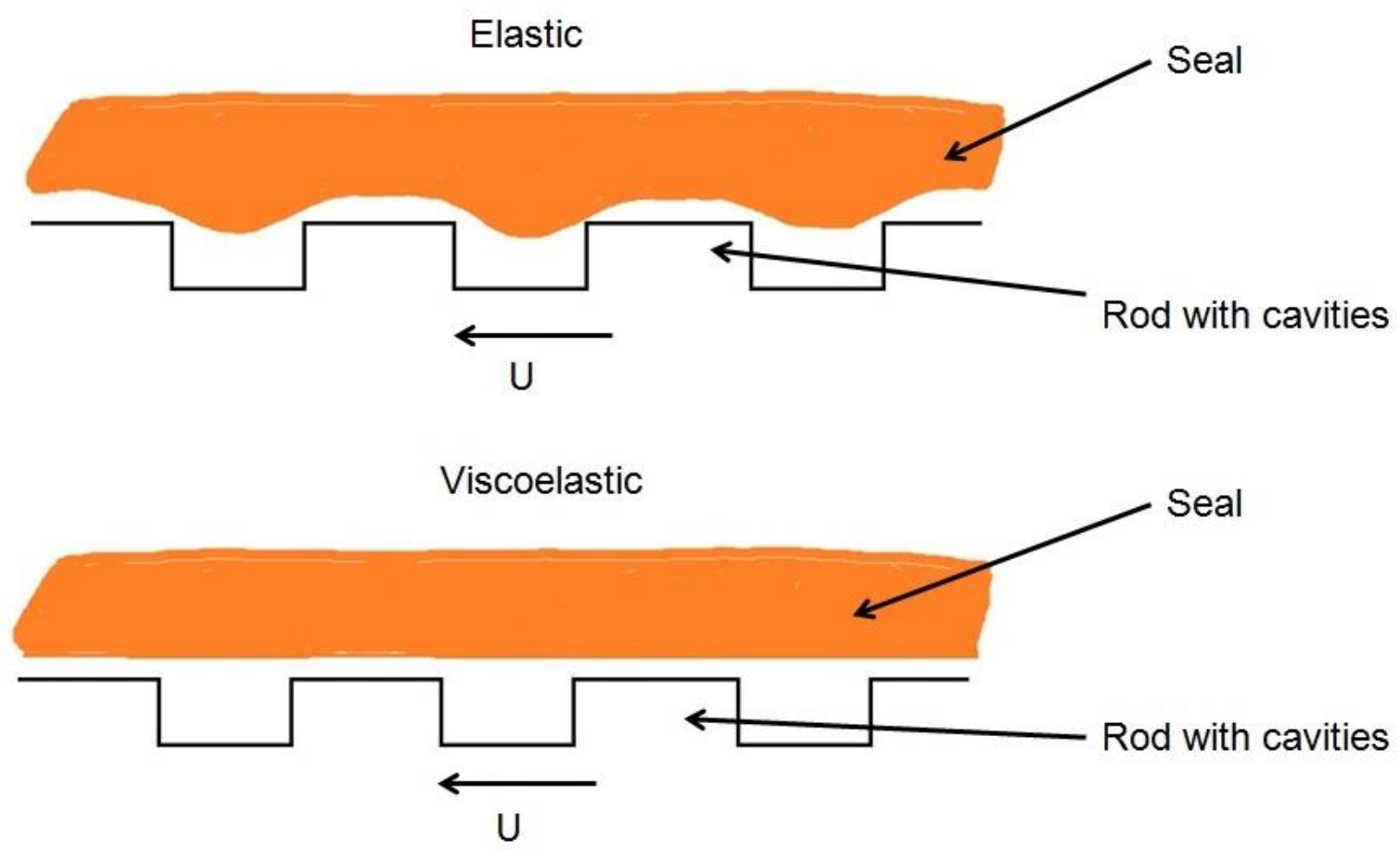
Fig. 4

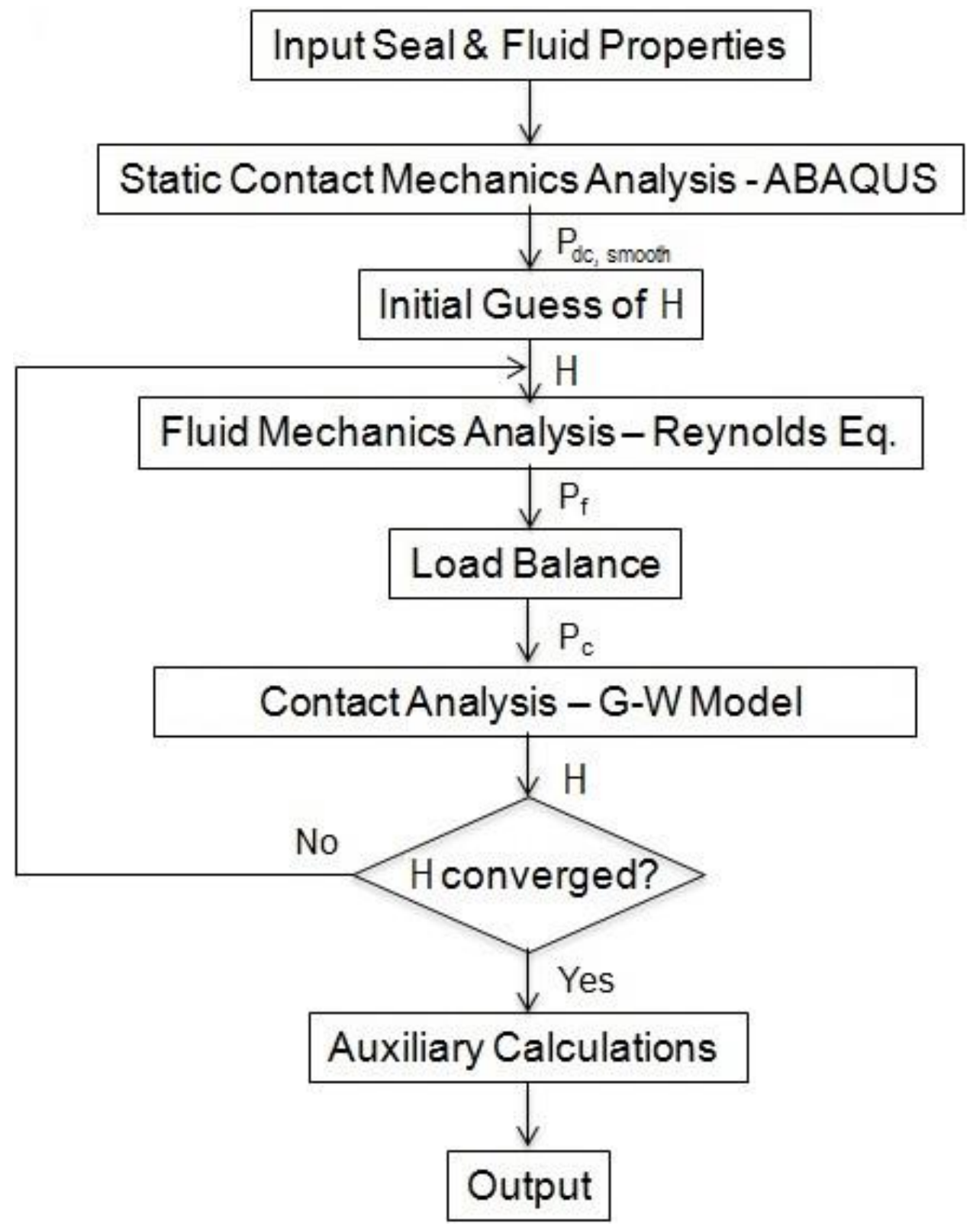


Fig. 5

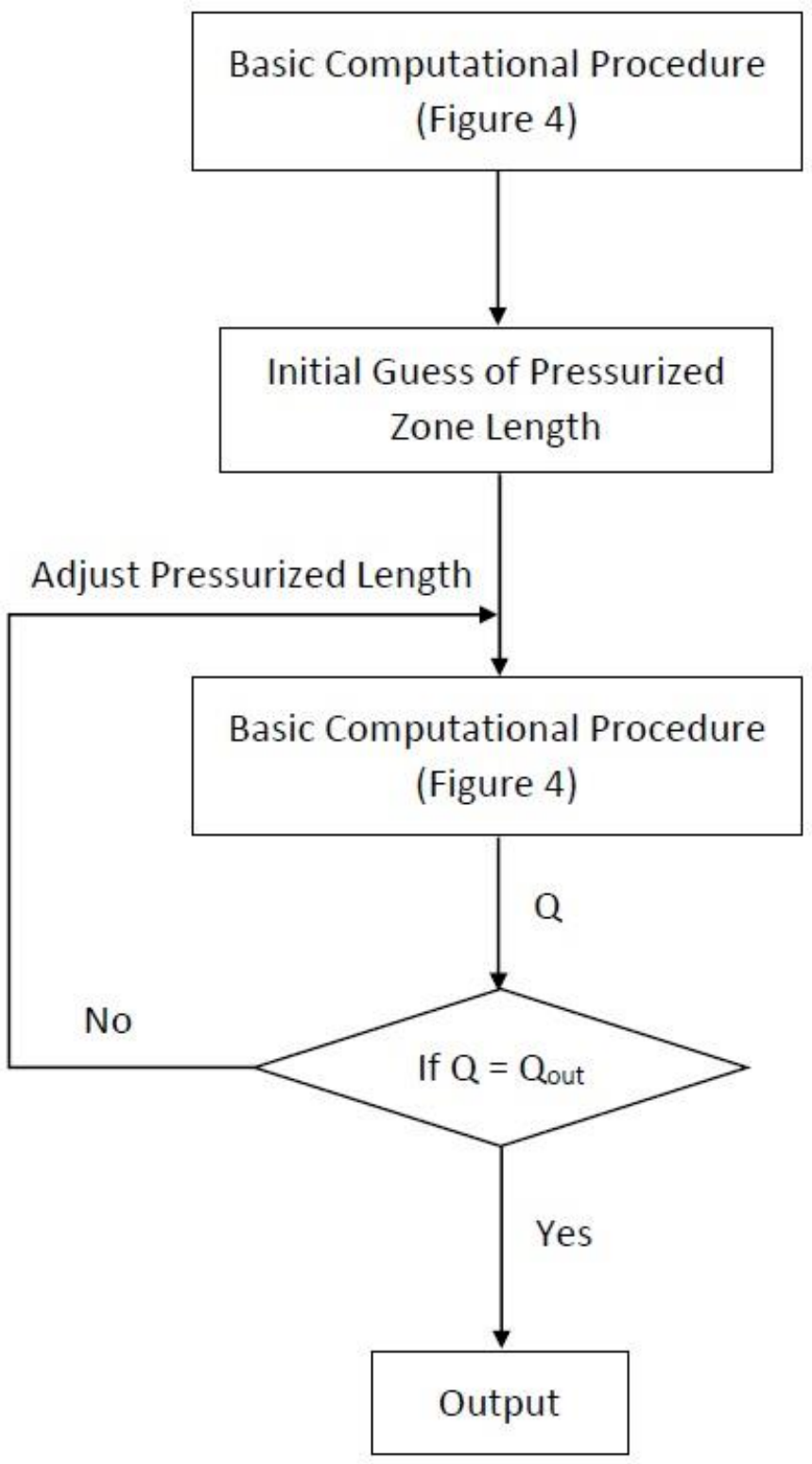


Fig. 6

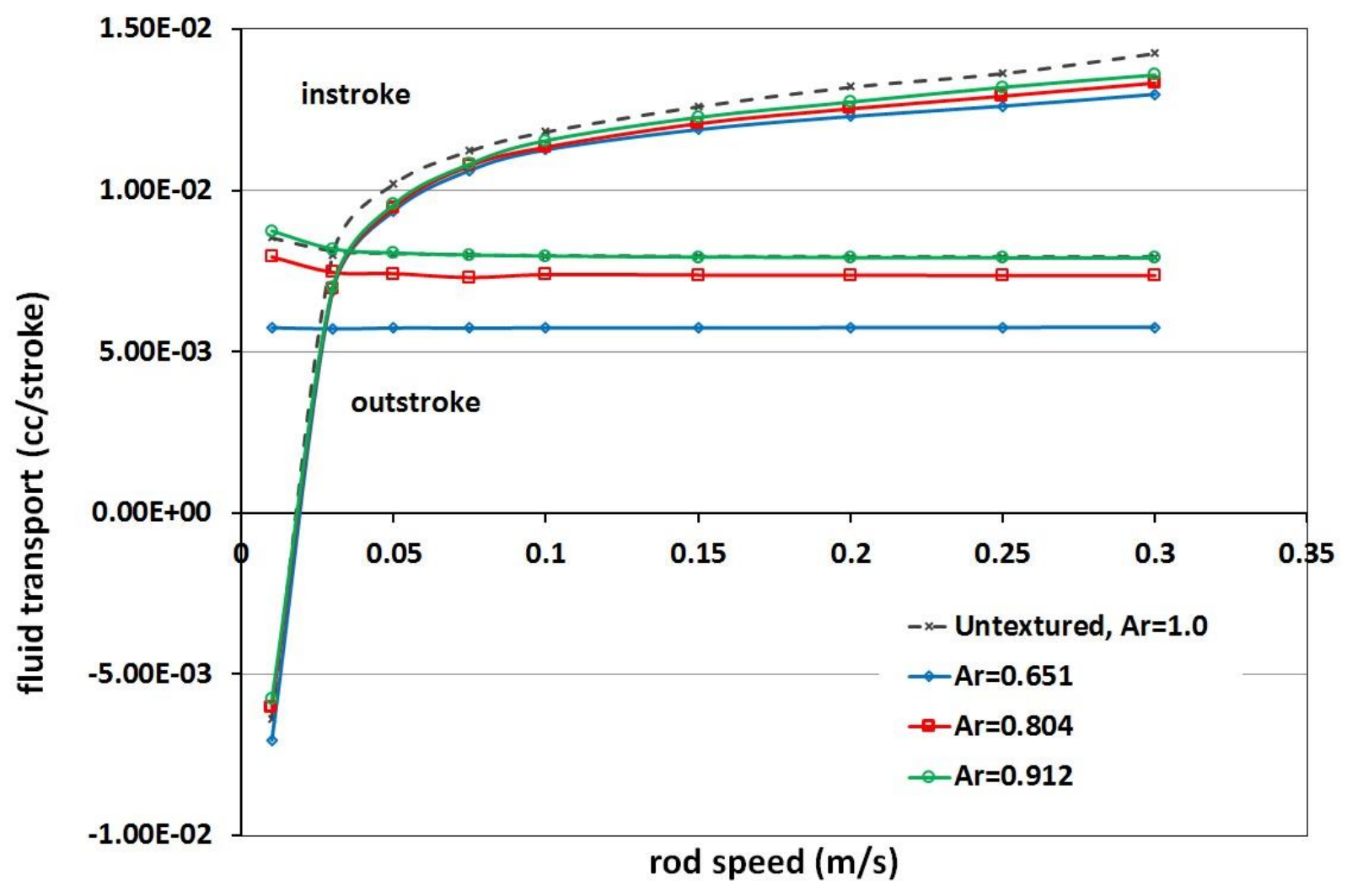


Fig. 7

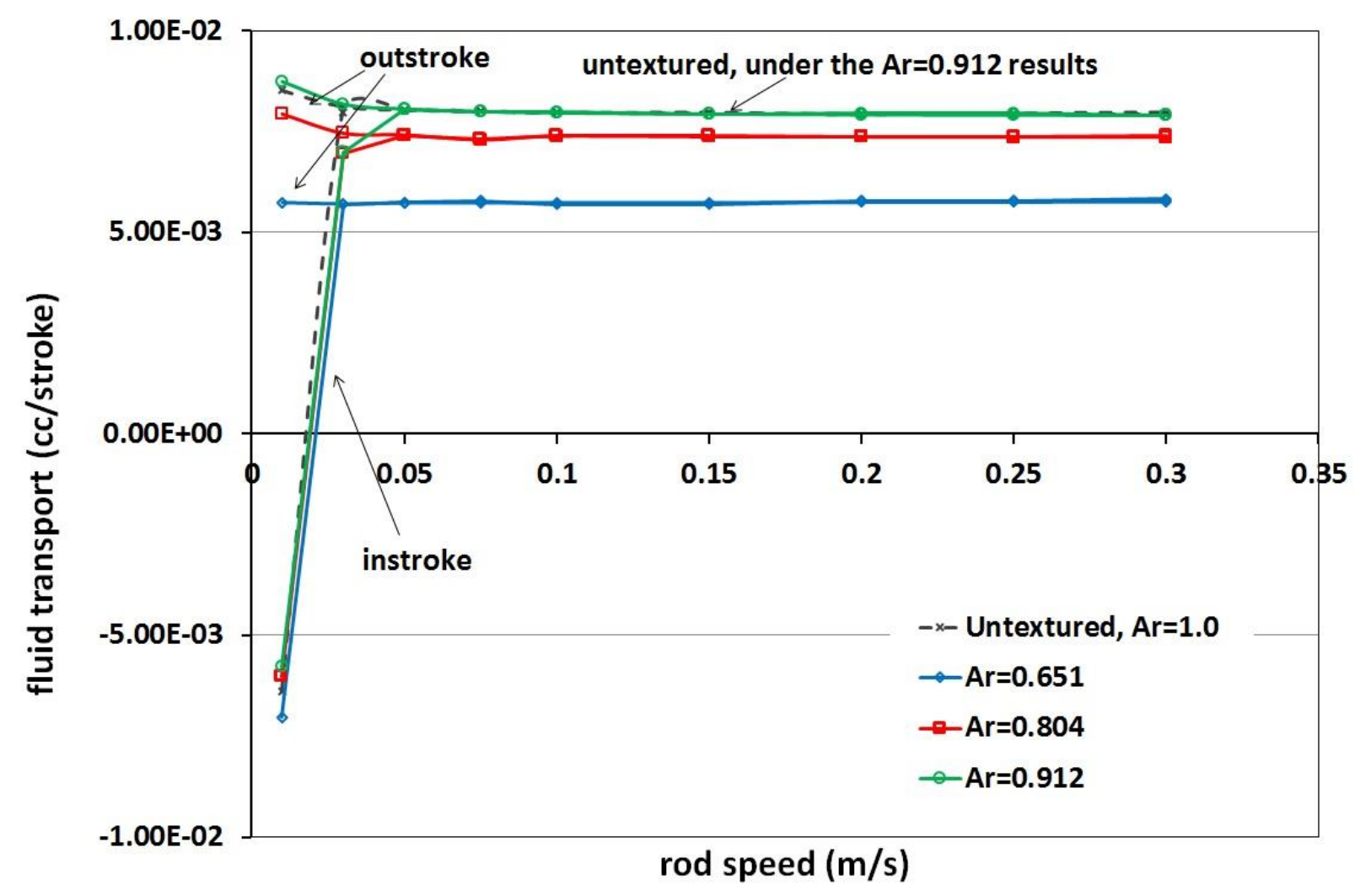


Fig. 8 .

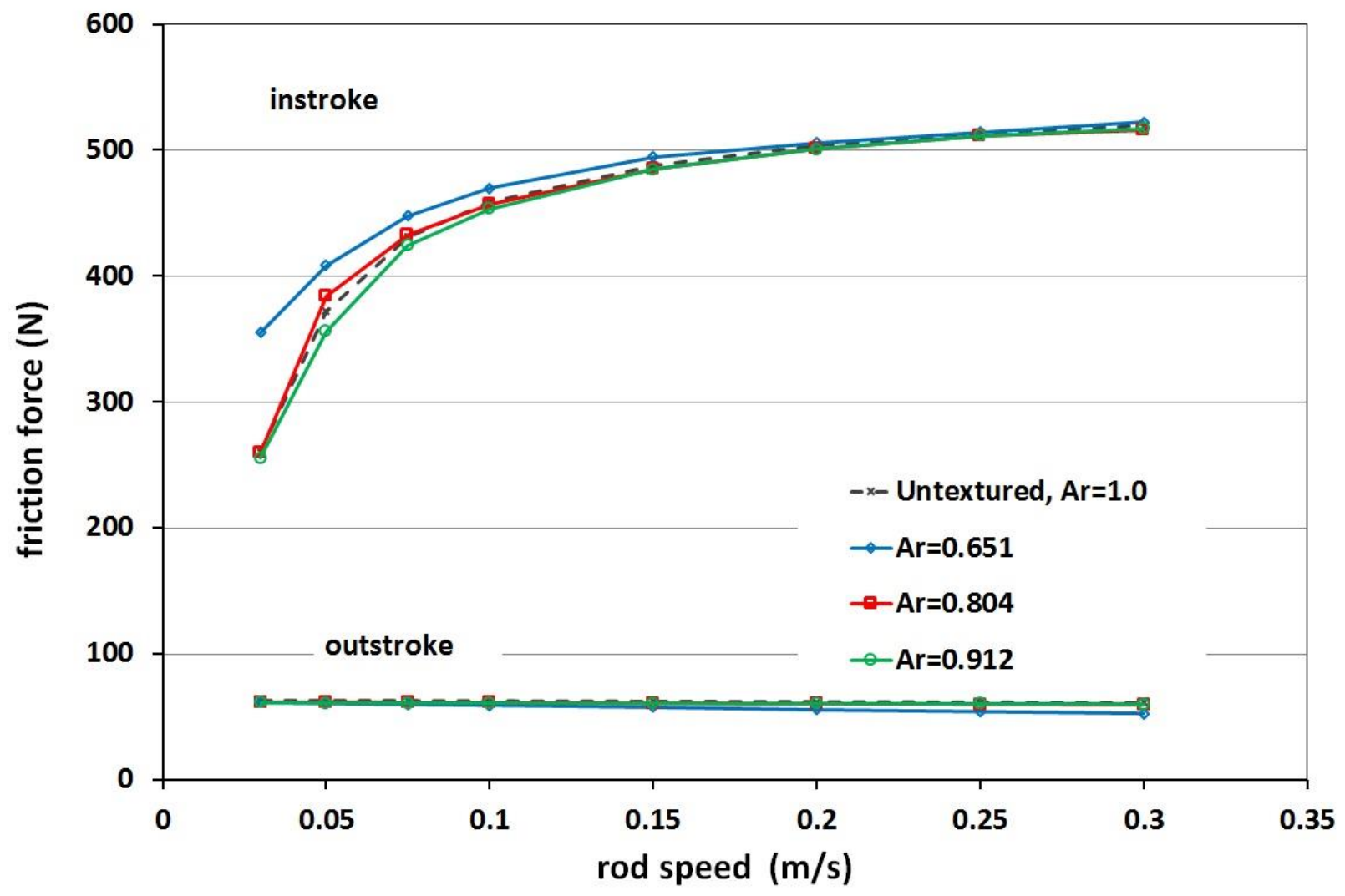


Fig. 9

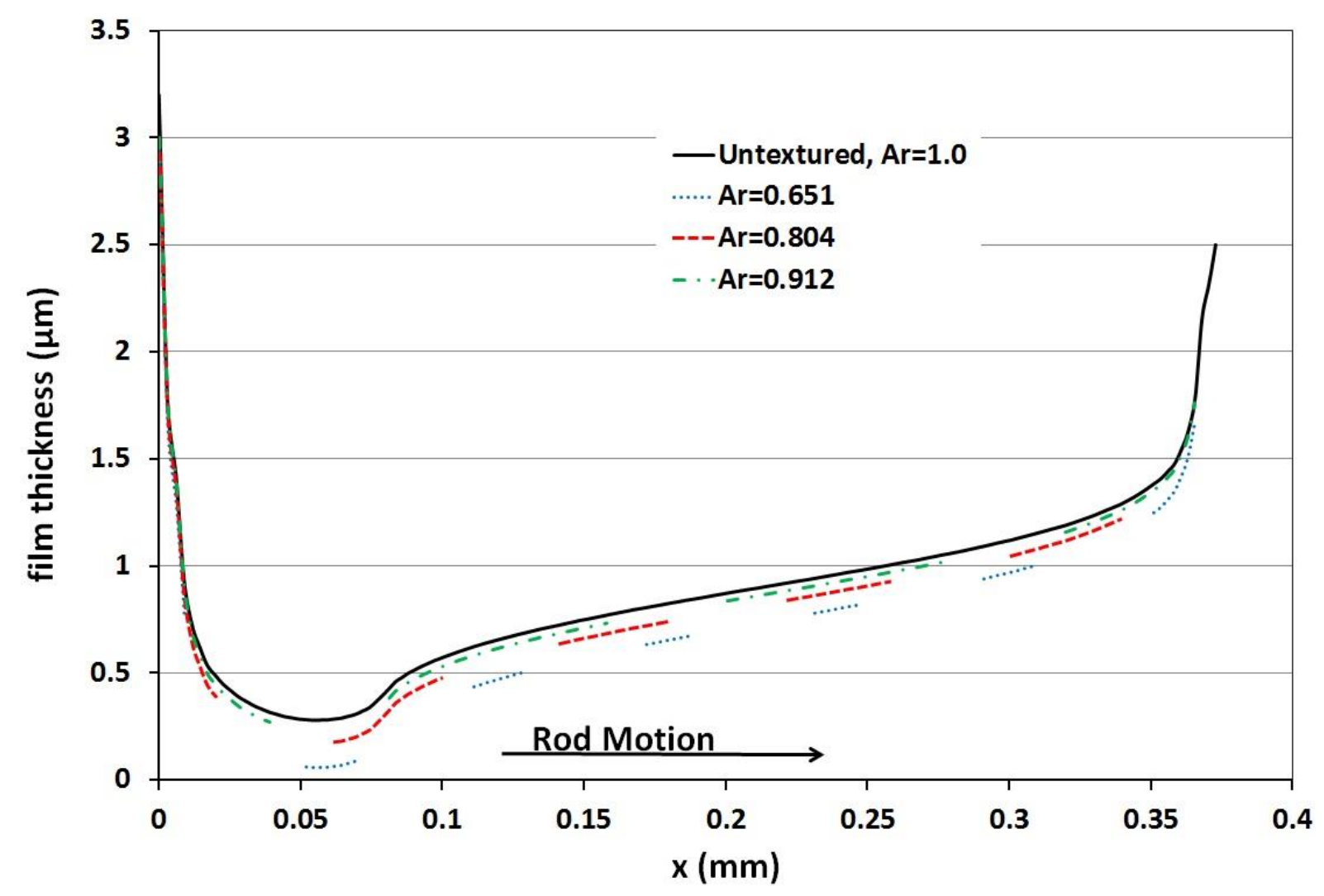


Fig. 10

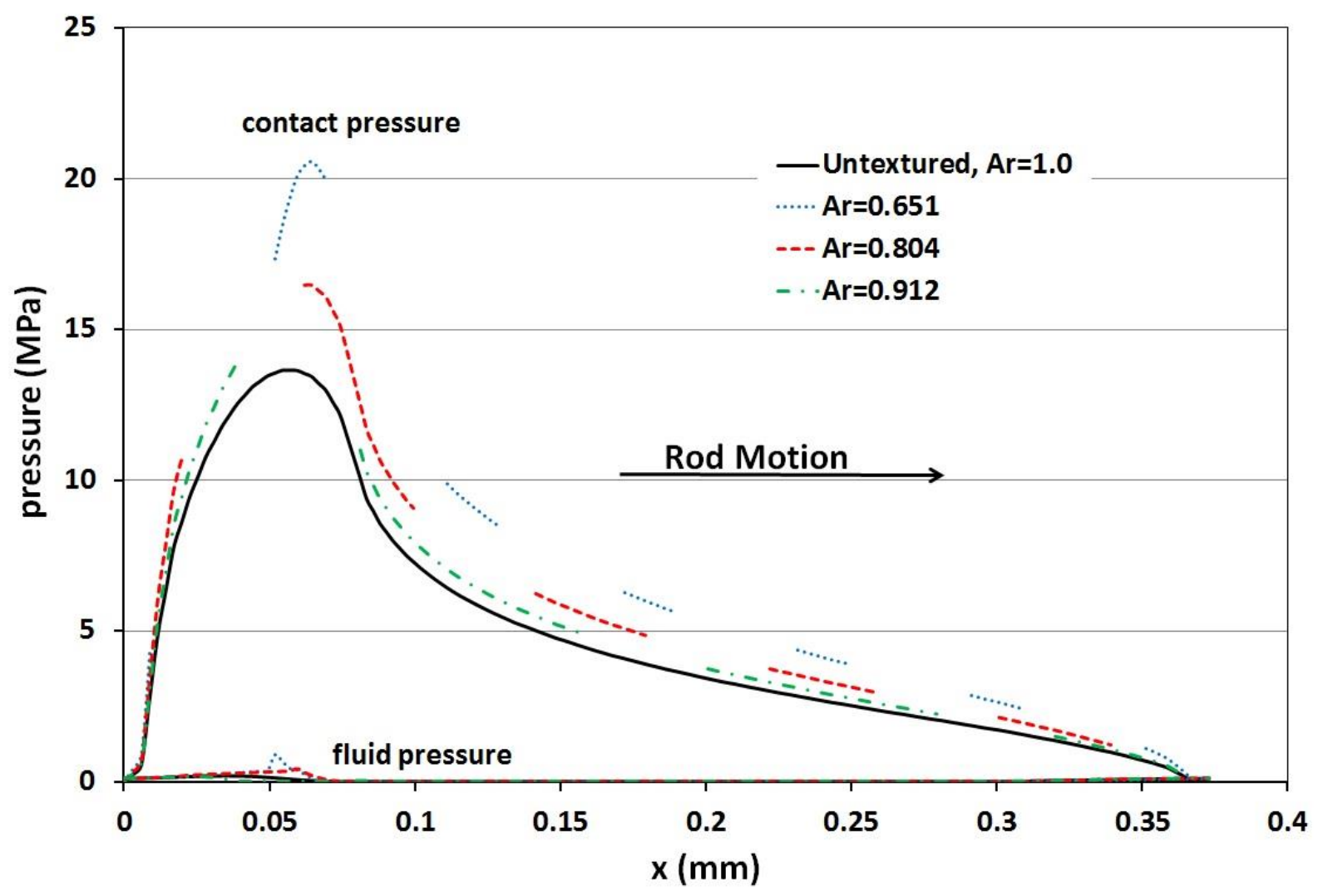


Fig. 11a

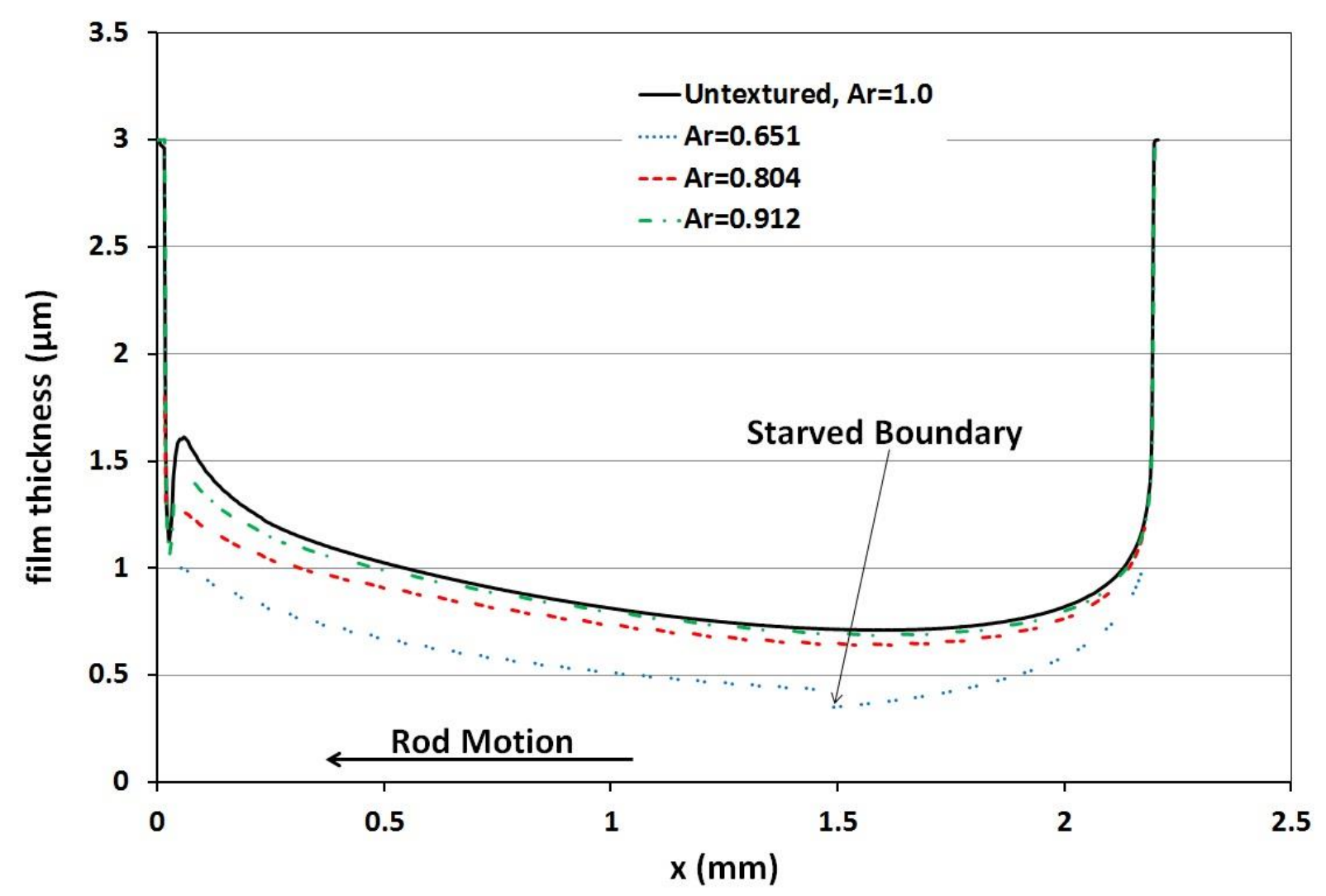


Fig. 11b

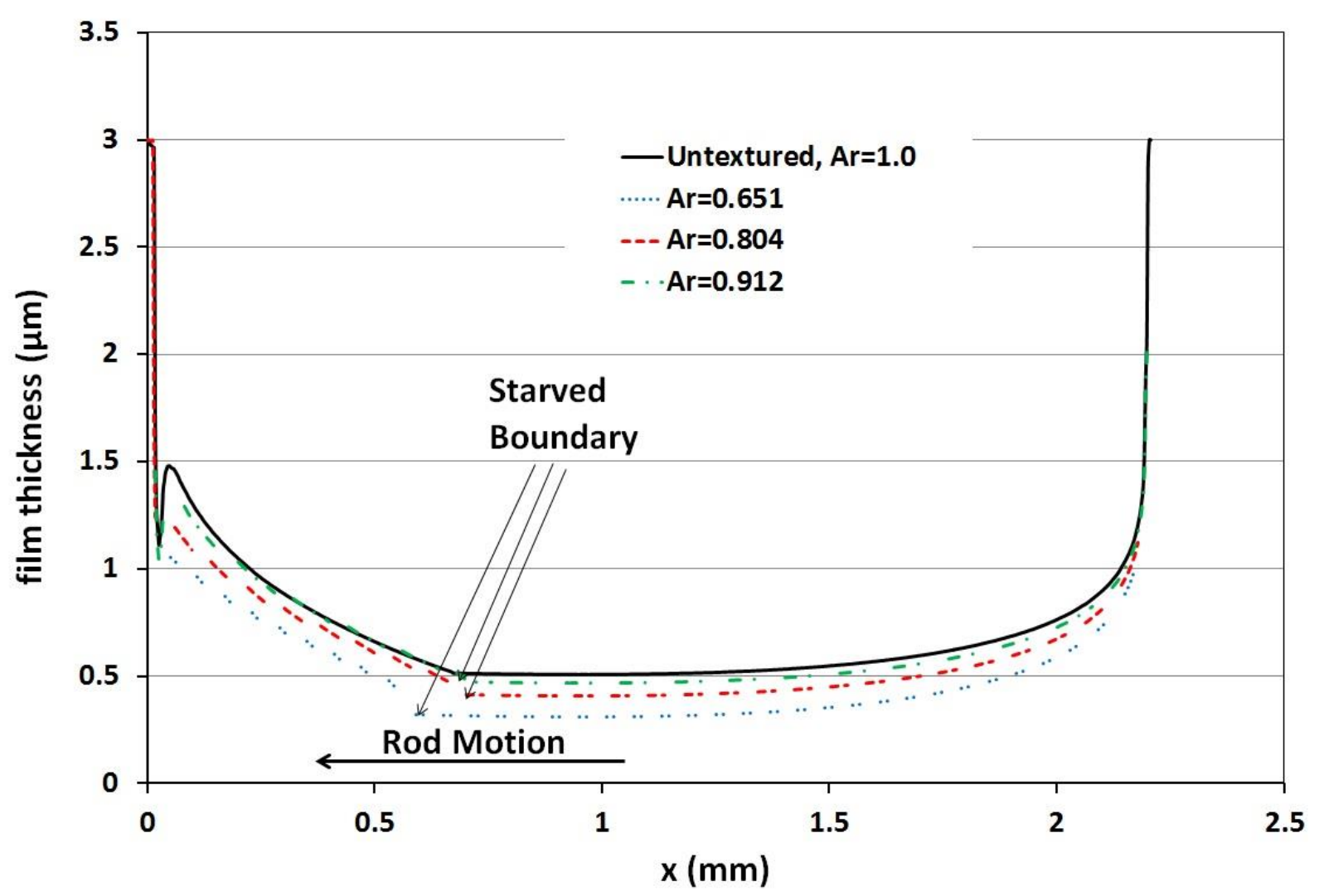


Fig. 11c

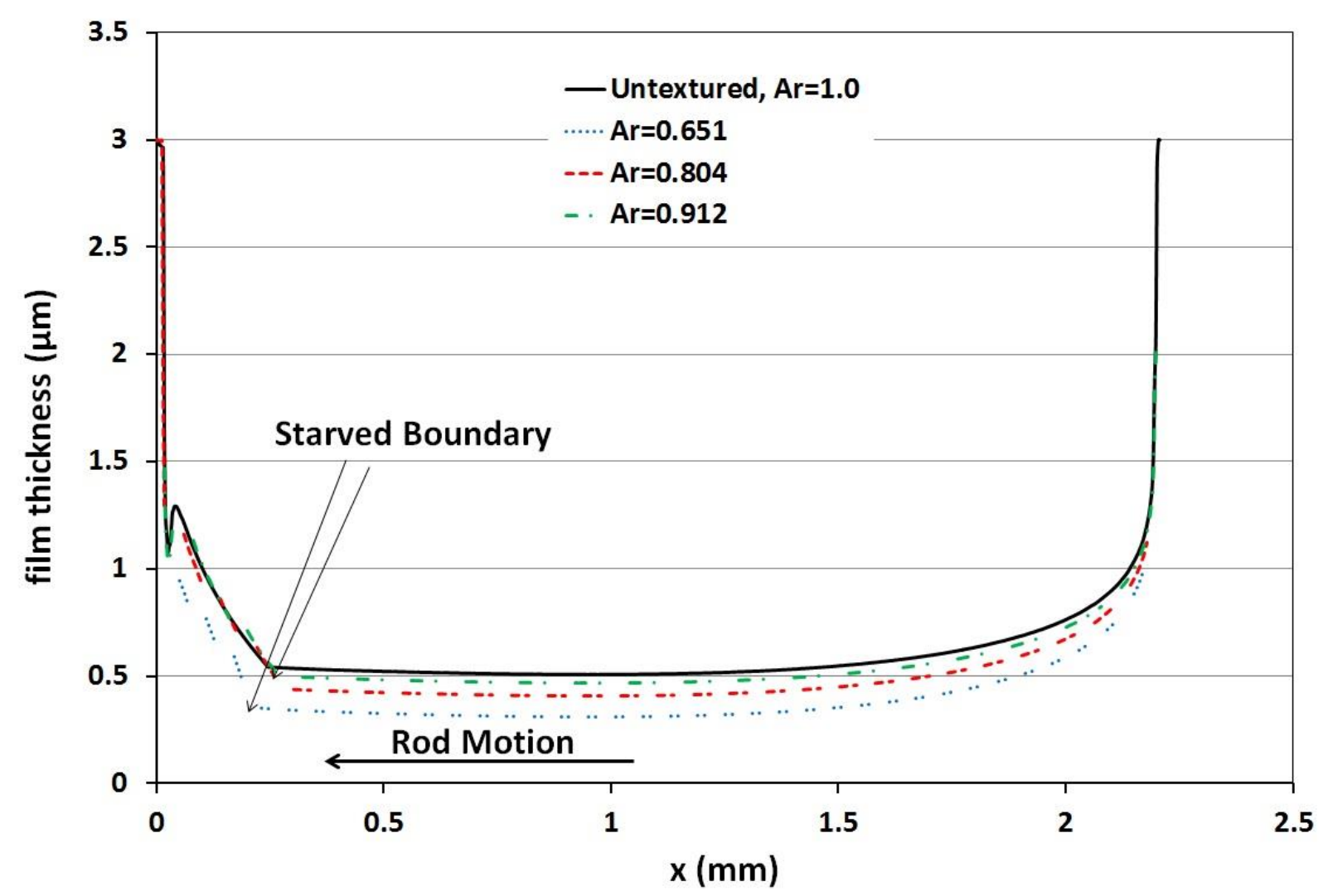


Fig. 12a

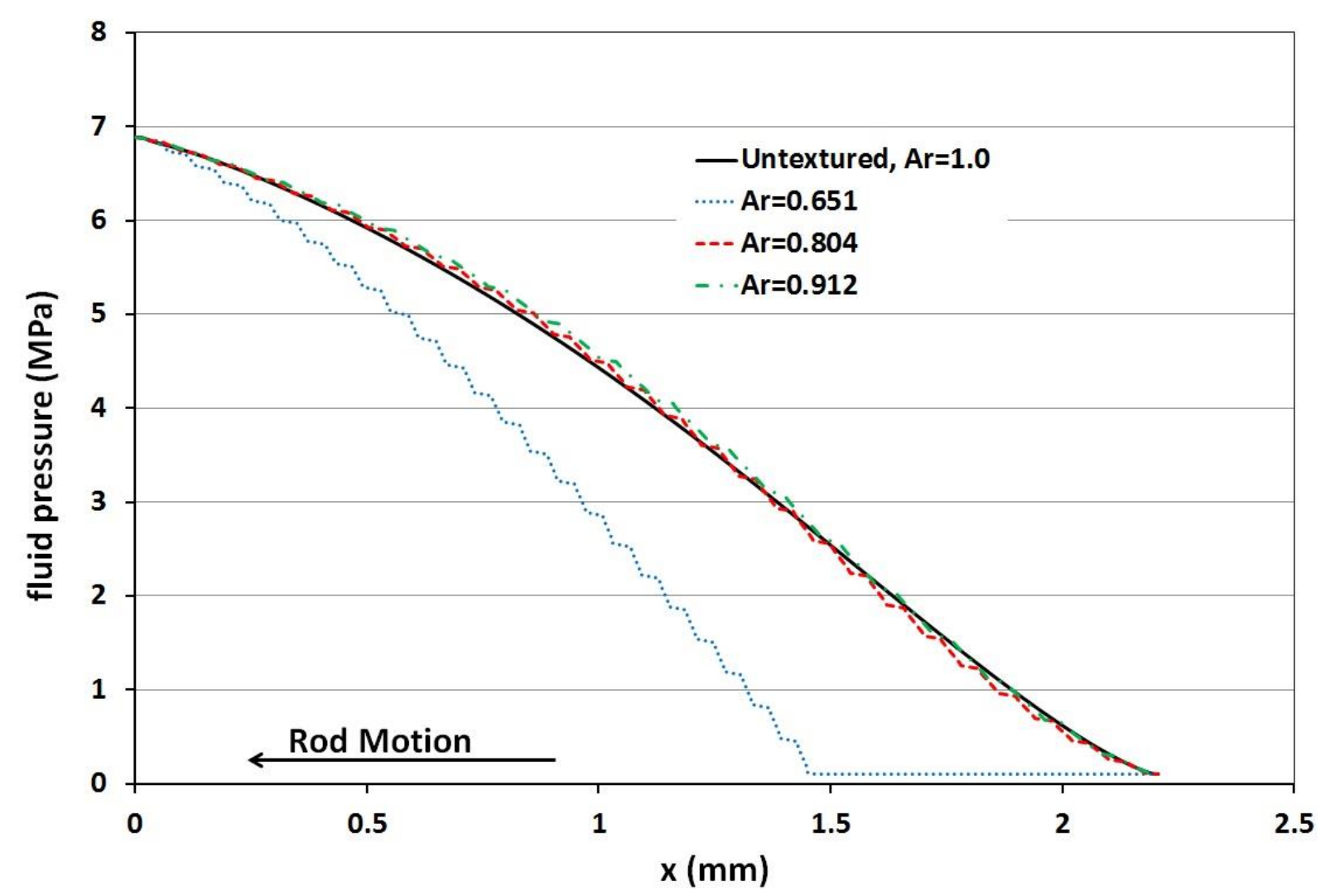


Fig. 12b

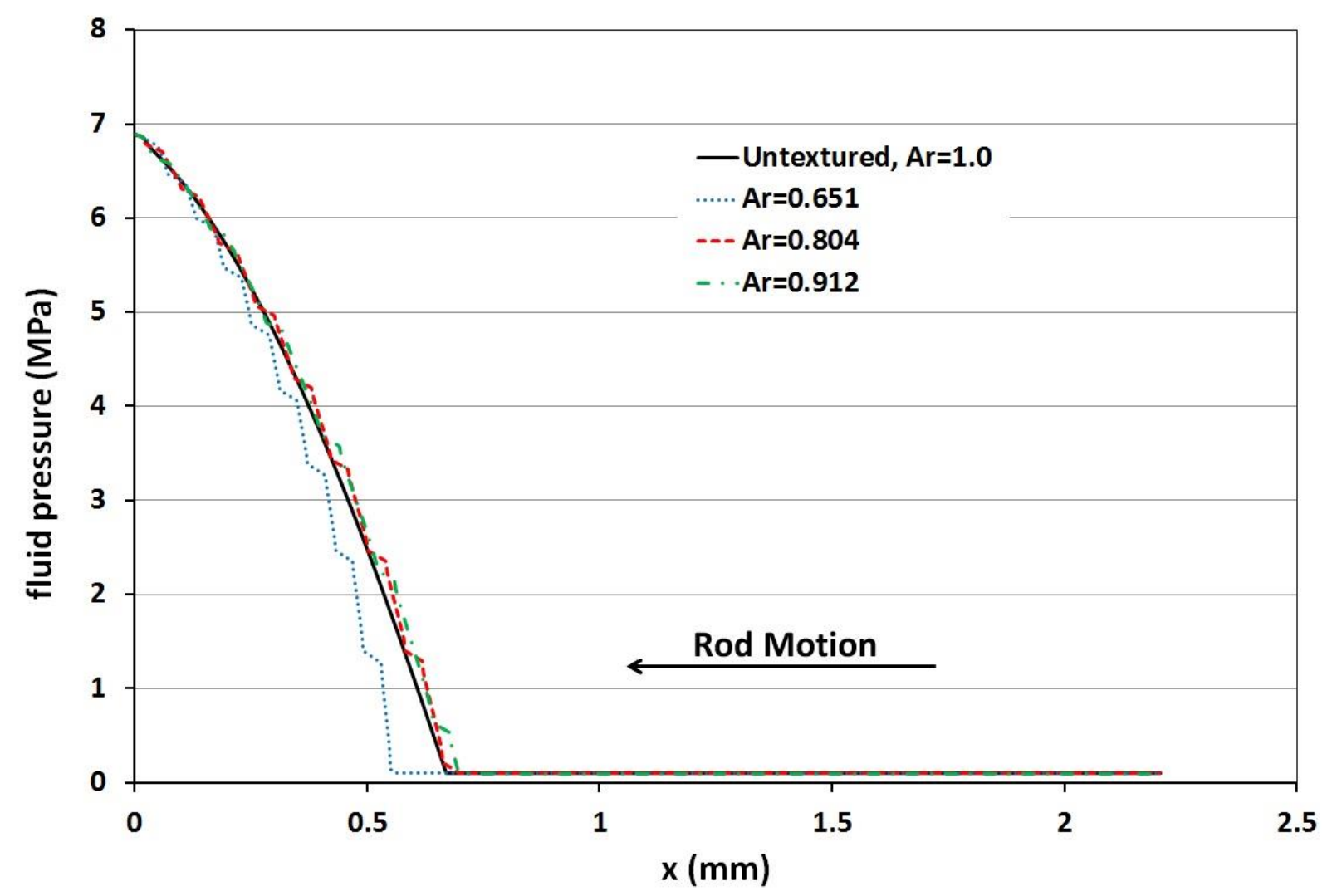


Fig. 12c

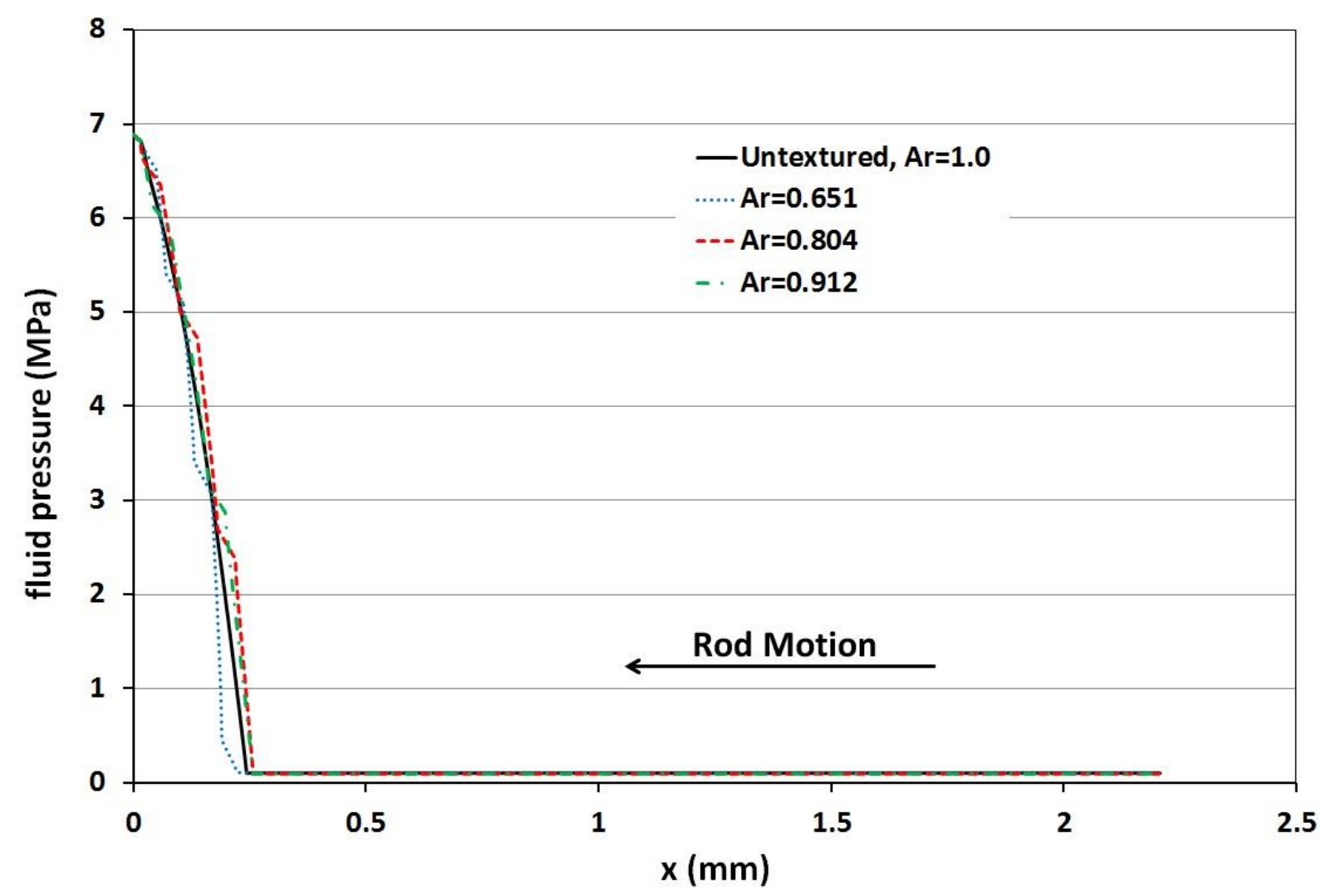


Fig. 13a

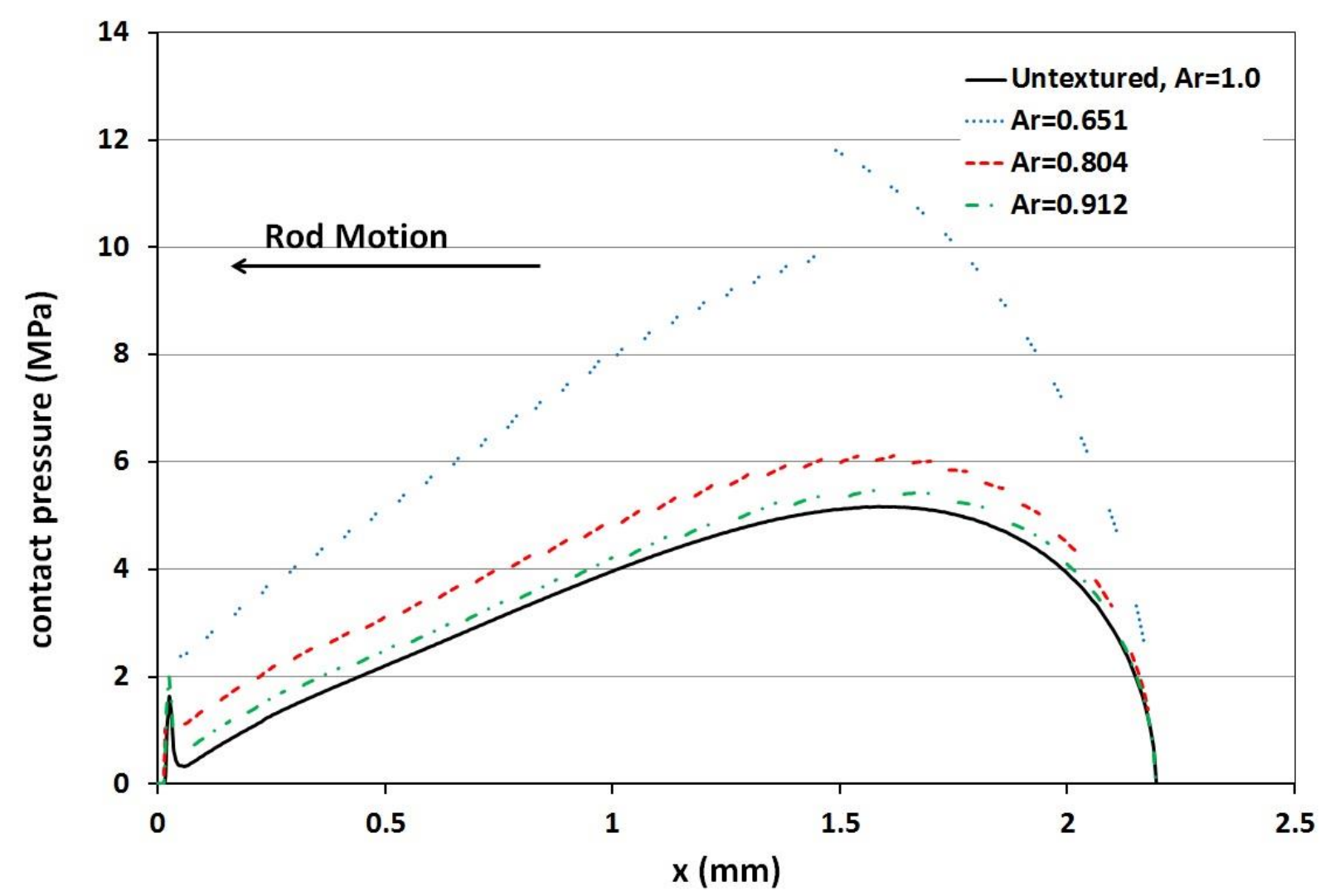


Fig. 13b

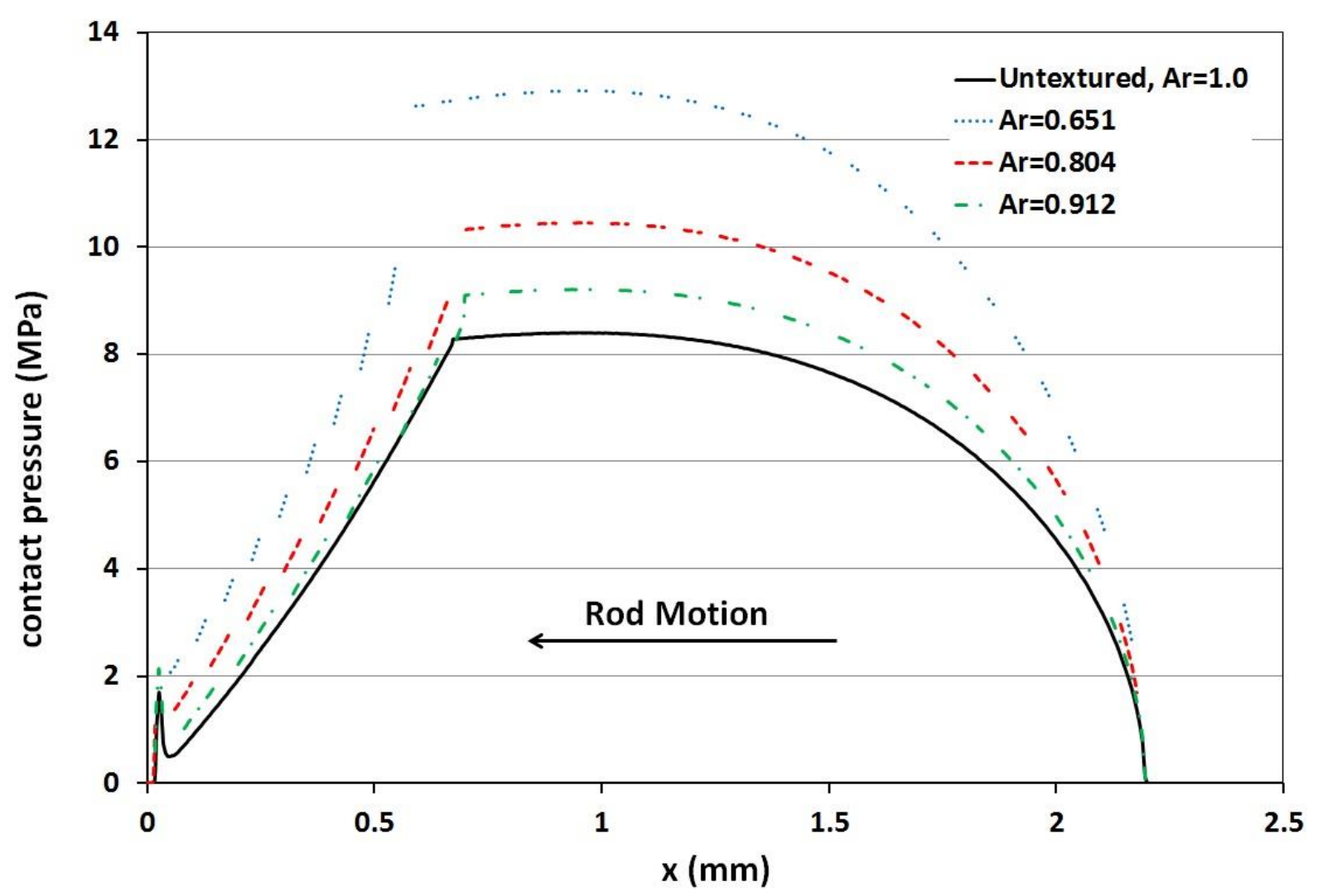


Fig. 13c

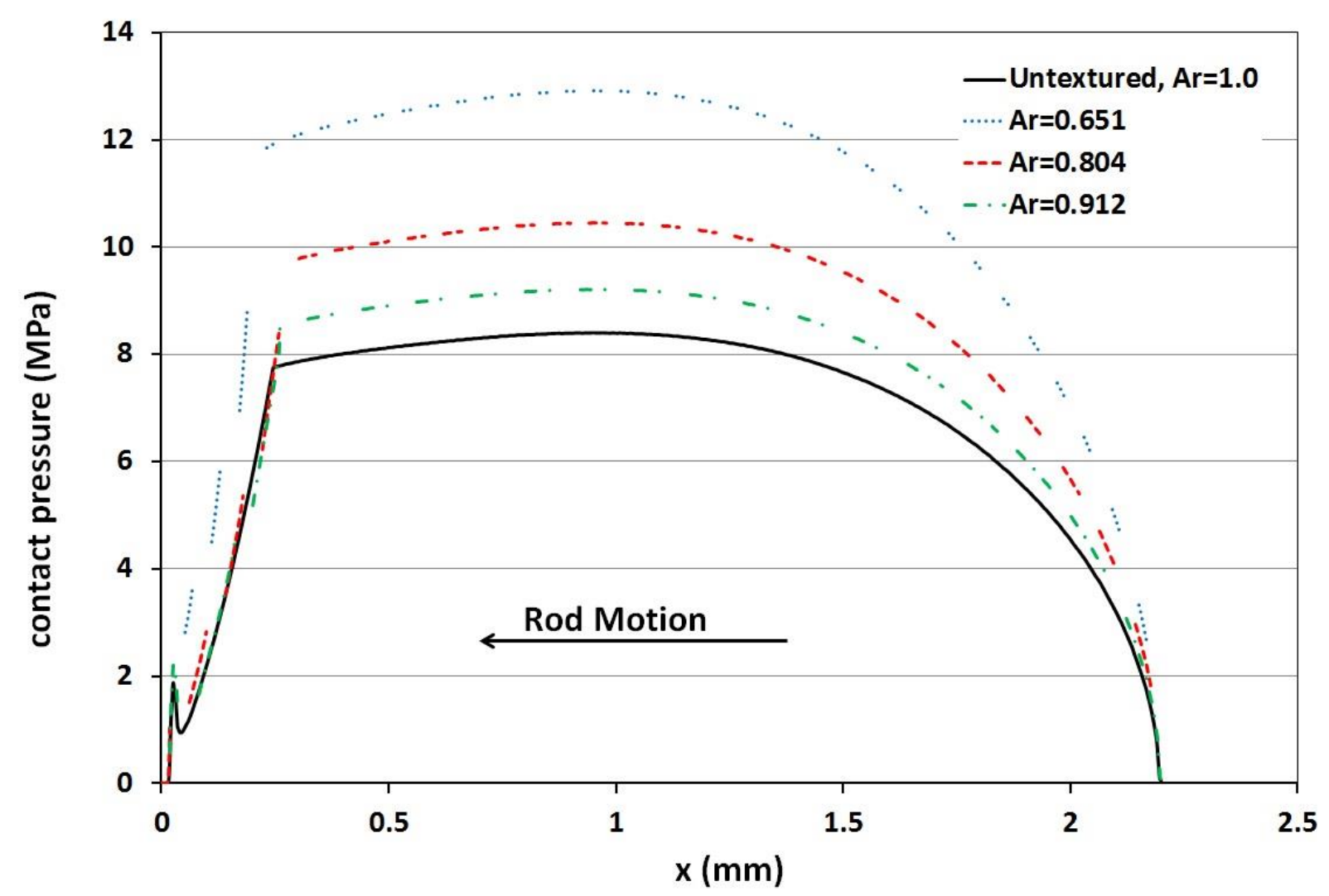


Fig. 14

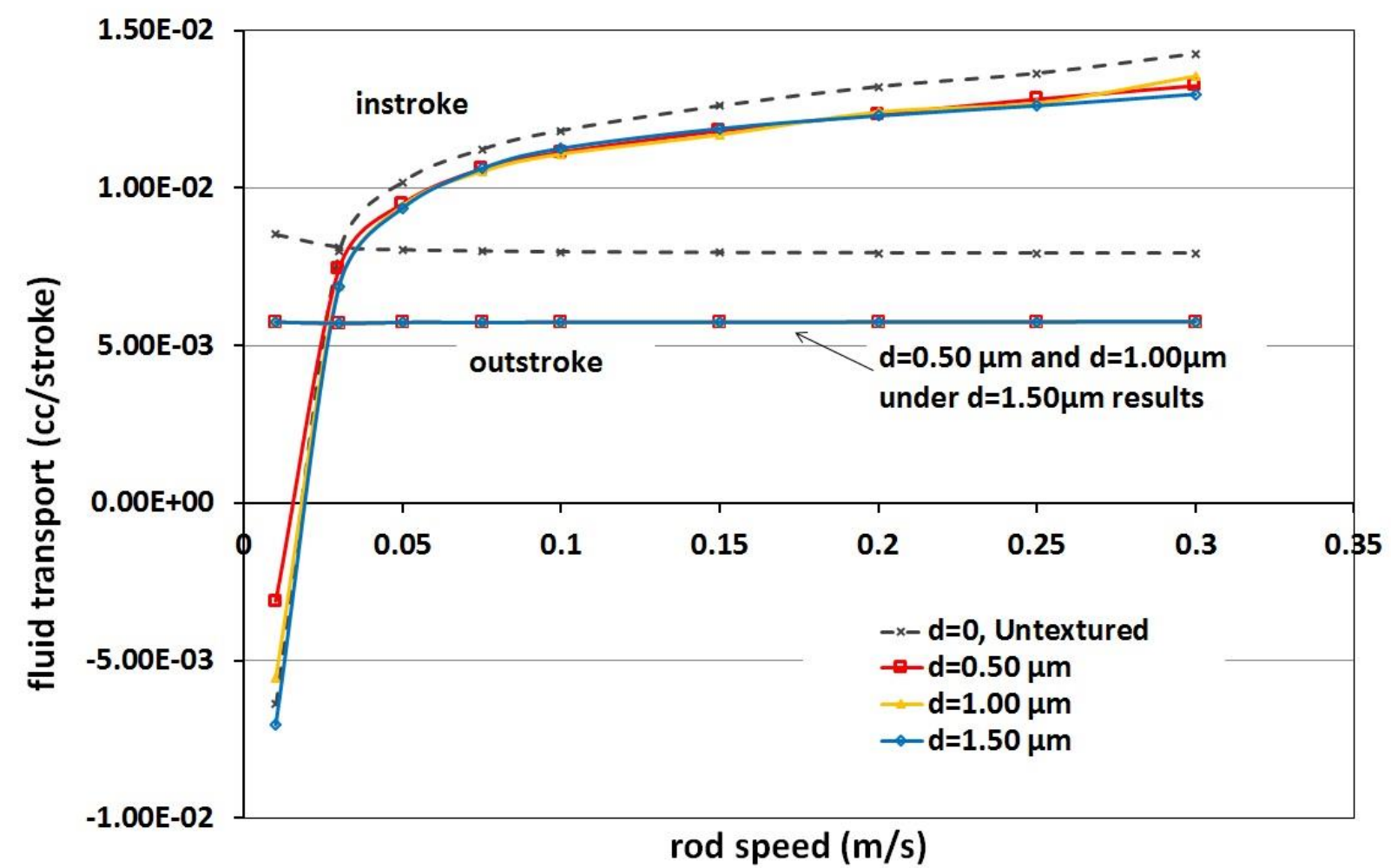


Fig. 15

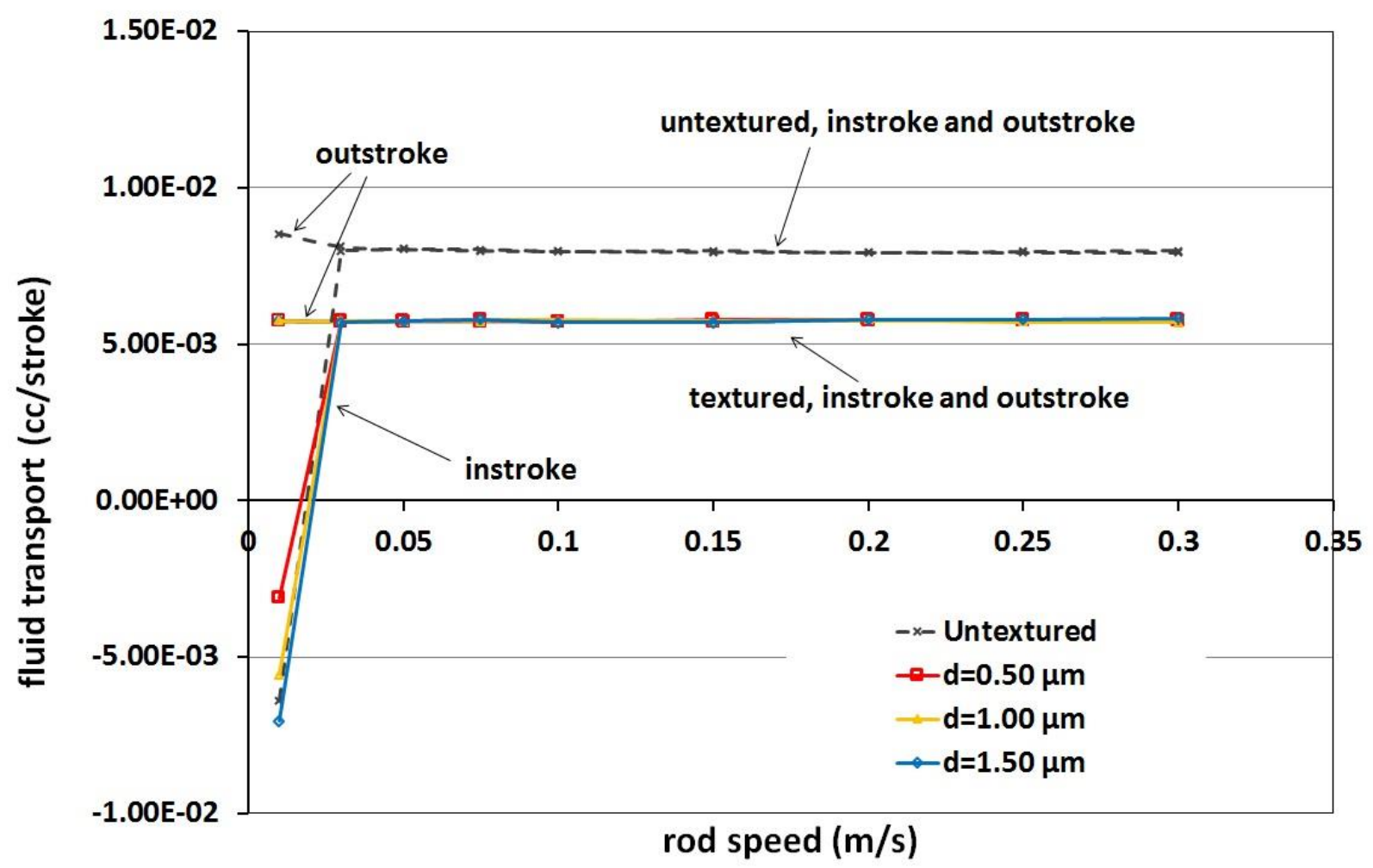


Fig. 16

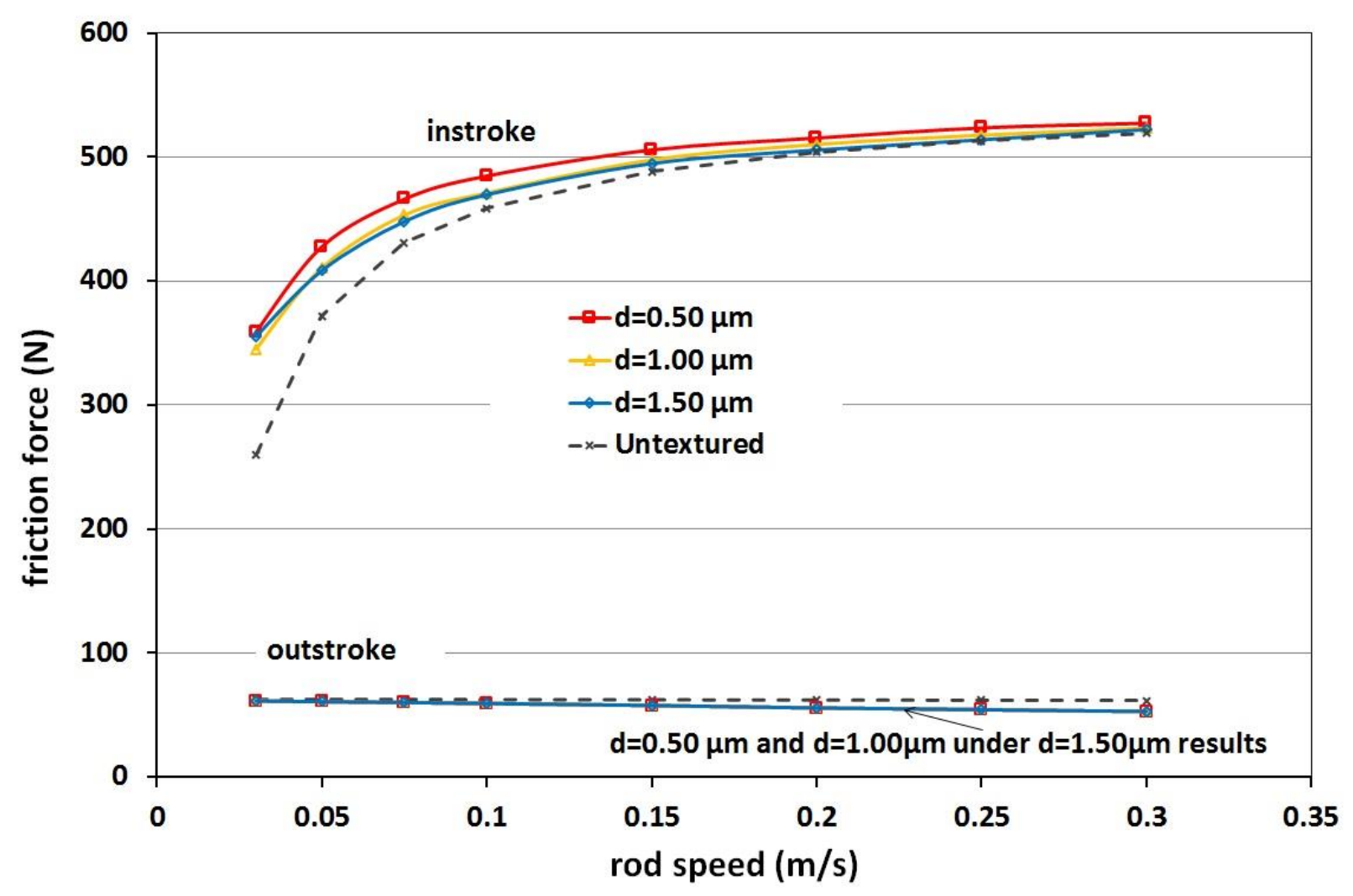

